NBSIR 78-1424

\title{
ICST/IAT Automation Project Bibliography and Brief Review of Literature on Machine-Tool Measurements for Automatic Control
}

Carol F. Vezzetti, J. Franklin Mayo-Wells, John S. Hilten, and Paul S. Lederer

Electronic Technology Division Institute for Applied Technology National Bureau of Standards

Washington, D.C. 20234

April 1978

Prepared for

Office of Developmental Automation and Control Technology, Institute for Computer Sciences and Technology, National Bureau of Standards 


\section{ICST/IAT AUTOMATION PROJECT \\ BIBLIOGRAPHY AND BRIEF REVIEW \\ OF LITERATURE ON MACHINE-TOOL \\ MEASUREMENTS FOR AUTOMATIC CONTROL}

Carol F. Vezzetti, J. Franklin Mayo-Wells, John S. Hilten, and

Paul'S. Lederer

Electronic Technology Division

Institute for Applied Technology

National Bureau of Standards

Washington, D.C. 20234

April 1978

This is an interim report. The work described constitutes the first stage of a more complex effort, results and conclusions are not necessarily those that would be included in a summary report.

\section{Prepared for}

Office of Developmental Automation and Control Technology, Institute for Computer Sciences and Technology,

National Bureau of Standards

Contribution of the National Bureau of Standards, not subject to copyright

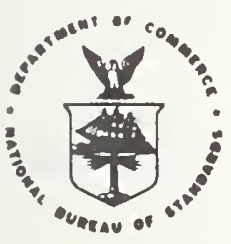

U.S. DEPARTMENT OF COMMERCE, Juanita M. Krops, Secretary

Dr. Sidney Harman, Under Secretary

Jordan J. Baruch, Assistant Secretary for Science and Technology

NATIONAL BUREAU OF STANDARDS, Ernest Ambler, Director 



\author{
Carol F. Vezzetti, J. Franklin Mayo-Wells \\ John S. Hilten, and Paul S. Lederer \\ Electronic Technology Division \\ Institute for Applied Technology \\ Washington, D.C. 20234
}

\title{
ABSTRACT
}

An English-language literature survey focused on machine-tool measurement related to wear was undertaken to ascertain the types of sensors used and measurements made by investigators throughout the world in support of machine-tool automation. The resulting review and bibliography constitute this document.

Key words: adaptive control; bibliography; control; cutting force; dynamic; force; load; machine tool; measurement; review; tool wear; torque.

\section{PURPOSE}

This brief review with accompanying bibliography was prepared to provide background information for the experimental investigation described in the companion document NBSIR 78-1423 li and for other work relating to the identification of suitable control inputs and calibration needs for automated, discretepart batch manufacturing.

\section{SCOPE}

Increasing interest in the automation of manufacturing processes, and in particular the goal of an "automatic factory", has resulted in a substantial number of papers concerned with in-shop, real time (on-line) measurement of machining parameters. Reflecting the interests of the Components and Applications Section, the bibliography emphasizes reports relating to the measurement of cutting forces and torques in machining operations, especially as these measurements contribute to the determination of tool wear, and a brief review is provided for these topics. Other topics discussed in the referenced documents include machine-tool practice and theory, automatic control of machine tools as a generic problem, and more specific interests such as chip formation, machinability of stock materials, chatter measurement and reduction, and tool life.

\footnotetext{
lHilten, J. S., Vezzetti, C. F., Mayo-Wells, J. F., and Lederer, P. S., Experimental Investigation of Drill-Bit Wear, NBSIR 78-1423 (February 1978 ).
} 
The bibliography (section 6), not intended to be exhaustive, has been arbitrarily limited to reports published in the English language, or for which abstracts in English are available. Most of the papers referenced were published after 1965.

\subsection{Sources}

References were obtained from several sources. With the cooperation of the NBS Library, a computer search of the COMPENDEX, INSPEC-PHYSICS, INSPECELECECOMPUT, and NTIS files on the Lockheed Information Systems data base was conducted. The search prescription terms were: MACHIN - + TOOL - + MEASUREMENT+ FORCE- or TORQUE- or VIBRATION-. (The hyphen indicates that any suffix may be added to the root term given.)

In addition, the following journals and other sources were reviewed for more recent references of interest:

Applied Science and Technology Index, 1975-1976;

Engineering Index, January-March 1977;

Metals Abstracts, January 1976-February 1977;

Annals of the International Institute of Production Engineering Research (CIRP), Volumes 18, 20-22;

Proceedings of the North American Metal-Working Research Conference, 1974; Journal of Engineering for Industry, January 1974-February 1977; and Manufacturing Engineering and Management, January 1974-February 1977.

\section{TOOL WEAR}

Several comprehensive surveys on tool wear have been published recently. A 1975 state-of-the-art survey by N. H. Cook et al. [45]* includes a matrix chart that lists the parameters that have been measured for various specific cutting processes, and identifies the organizations in which the work was carried out. This survey incorporates 84 "annotated references", that is, report citations with short summaries. (Most of these references have been incorporated into the bibliography.) Also in 1975, on-line tool-wear measurement work of the past decade was reviewed by M. P. Groover in a paper published by the Society of Manufacturing Engineers [77]. This survey divides reported work into seven ' lasses of measured variables or measurement principles and discusses the work in each class as a unit.

As explained in both these surveys, direct, in situ measurement of tool wear has not been achieved except in a few instances [67, 128], and therefore most determinations of tool wear that have been reported are inferred from measurements of other parameters.

3.1 Cutting-Force Measurement Methods - The cutting force developed during conventional three-dimensional machining may be considered to be the resultant of several components, of which the most significant are the main cutting force, defined as the force on the tool in the direction of the cut; the feed

*Figures in brackets indicate the 1 iterature references in section 6.2. 
force required to advance the tool into the work; and the reaction force on the tool in a direction perpendicular to the working surface. For purposes of determining tool wear, the most common measurements are of cutting force and feed force. A compilation of measuring systems suitable for dynamic cutting force measurements is given in a 1968 paper by Blankenstein [27].

In machining operations in which the tool rotates, such as drilling, milling, grinding, and the like, the main cutting force is often measured as the torque developed in the tool or imposed on the workpiece. Machining torque has been measured by a number of methods. Conventional methods of measuring stress, such as the use of strain gages cemented to"the tool shaft or spindle or to the fixture restraining the workpiece $[23,24]$ have been employed. Other direct methods for measuring torque include the use of piezoelectric [182] and magnetic [116] dynamometers. A common indirect method involves measurement of the electrical power consumed by the drive motor $[63,123]$. A less common direct method depends on the magneto-striction effect and has been applied to milling. A special tool spindle plated with a magnetic material is required. Tensile and compressive stresses on the spindle surface are produced when the spindle transmits torque from the machine drive to the rotating cutter. As a result of the presence of these stresses at $45 \mathrm{deg}$ to the spindle axis, the magnetic permeability becomes anisotropic, and the magnetic coupling between an exciting coil and a sensing coil is unbalanced. The unbalance induces an output signal proportional to the torque applied to the spindle. In the apparatus described, spindle deflection is also measured (magnetically with a separate deflection-sensing coil); the deflection signal is used as input for adaptive control of feed rate [129]. All of the above methods have the disadvantage that slip rings, or their equivalent, are required for electrical contact (the disadvantage arises because slip rings are sources of noise that interferes with the desired signal). In machining operations in which the tool is stationary, such as with the lathe, the main cutting force has usually been determined by measuring deflections of the tool itself or of the tool holder $[57,110]$.

Forces for all types of conventional machining methods are also commonly determined through deflection measurements of tool [11] or workpiece fixture [159], as appropriate. These measurements have been made using strain gages $[42,57]$ and piezoelectric [182] or magnetic [191] transducers. There is at least one commercially available line of piezoelectric transducer systems designed for measuring cutting forces during machining operations [102,164]. A number of workers have made use of a cantilever design of workpiece fixture or tool holder to improve the sensitivity of the measurements $[14,87]$.

3.2 Vibration Methods of Tool-Wear Measurements - A number of schemes, some commercially available [100], are based on the observation that a worn tool produces different sounds compared to those produced by a sharp one [190]. The vibrations in the tool or workpiece or the sound generated during cutting are recorded and analyzed to develop a signature for the individual machining operation [90]. Changes in signature may be interpreted as indicators of tool wear (or, in extreme cases, of catastrophic failure). Several investigators believe that the spectral energy distribution of the vibration signal shifts to emphasize high frequencies as the tool wears [190]. Vibration signatures are also used to detect incipient malfunctions in machine tools and to monitor machine condition $[37,72,99]$. 
3.3 Temperature Methods of Tool-Wear Measurement - Temperature rise and rate of rise have both been reported as means for determining tool wear. In some embodiments, the thermal emf generated between the tool and workpiece is used directly as an indicator $[42,68]$; in others, "remote" thermocouples inserted into the tool near the cutting edge are used $[23,113]$. Work has also been reported in which infrared sensing of tool temperatures has been attempted $[70,189]$.

\subsection{Electrical Resistance Methods of Tool-Wear Measurement - Constriction} resistance between the workpiece and the tool changes as the wear land (and, therefore, the area of contact) increases; this phenomenon has been employed as an indicator of tool wear $[56,68]$. In other related methods, a resistive element. [187] or a resistance network [165] is attached to the flank surface of the tool. As the tool wears, insulating and resistive material is also eroded, thus changing the resistance of the element or network. A disadvantage of these measurement methods when applied to rotating cutters is the necessity for slip rings.

3.5 Other Methods of Measuring Tool Wear - Tools with radioactive material implanted in the wear zone have been investigated for tool-wear measurement. The activity of the chips is monitored, giving an indication of the amount of tool material worn away [83]. A modification of this method using a small implanted radioactive particle has been proposed; the position of the particle would be carefully controlled and the activity of the tool would be measured following a cycle of use. Activity would be expected to drop to background levels when the particle was completely worn away [46].

Methods for measuring tool wear by optical means have been applied to operations with a rotating cutter and have required that the tool be removed for measurements of the wear land or other tool dimensions with a toolmaker's microscope [108]. However, a few on-line optical measuring schemes have been reported for use in machining operations in which an interrupted cut makes the cutting face of the tool available for direct examination for some fraction of each tool revolution [67]. At least one of these methods uses a vidicon camera and a remote video display [128].

\section{DRILLING MEASUREMENTS}

Because the experimental approach of the Components and Applications Section has been to instrument a drill press, it is of interest to this work to identify several important papers specifically devoted to drilling operations.

R. A. Williams, in his paper "A Study of the Drilling Process'[194], introduces a geometric model of drilling action from which he derives equations capable of predicting drilling forces and torques for a given drilling operation in a given material, although the workpiece factor is empirical. Comparison of predicted with experimental results shows reasonable agreement for the limited workpiece specimens. Williams provides 19 references which have not been repeated in the bibliography. In the paper "Sensing of Drill Wear and Prediction of Drill Life"l [168], K. Subramanian and N. H. Cook discuss the use of torque, feed force, and power as indicators of tool conditions. Relations are derived for expressing torque and feed force as functions of wear-land geometry and 
hence of drill wear. Workpiece hardness is identified as a particularly crucial parameter with respect to drill bit condition. An interesting paper by $V$. Solaja and J. Stanic, "Selected Results from a Project on Drilling" [160], summarizes work carried out at the University of Belgrade for the Yugoslavian metal-wurking industry. This group reports the development of a mathematical model adequate for the prediction of drill-bit life for a given application. Several of the detailed reports are available, but in the Serbo-croatian language.

\section{CONCLUSIONS}

A brief examination of the literature describing machine-tool measurements, particularly as such measurements may be applied to adaptive control of machining operations, shows little unanimity in either the choice of methods or the interpretation of measurement results. A more careful review of the work to date changes the picture but little. Those who address the question agree that the in situ measurement of tool wear required by automatic control systems is not a generally solved problem. Nevertheless, vibration-signature methods making use of digital processing show promise of being applicable to many machining operations without requiring modification of machine tool or fixturing, and the interpretation of measurements of force, torque, and power appears to rest on a developing and expanding understanding of specific machining operations. Indeed, embodiments of these approaches are commercially available as components and as at least one system [116].

Many measurements of various quantities have been made, but many gaps remain to be filled in the matrix of possible useful measurement knowledge for diverse operations. Because in the literature reviewed few investigators reported ranges of variables such as measurand magnitude and frequency, it is difficult to develop any global picture of what has been done. Most mechanical parameters have been measured in the frequency range 0 to $5 \mathrm{kHz}$, but beyond that rather meager statement, little that is general can be said.

As the measurement methodology itself is in a state of development, the conclusion from reviewing the literature that calibration needs have not been broadly addressed comes as no surprise. Although some workers report static calibrations of their specific measuring means, these calibrations usually employ methods suitable for the laboratory but not for the machine-shop floor. Dynamic calibrations are almost totally lacking. Methods such as the use of instrumented or calibrated artifacts for directly comparing measurement results from different measurement systems or from a single system applied successively to several individual machine tools have not been reported.

As machine-tool measurement systems move out of the laboratory into commercial use with adaptive and other control systems, the need for calibration of the basic sensing means and for methods of determining sensor performance will become a marketplace issue. As has happened before in many fields, there is a real danger that calibration methods will not be available to match the technology. 


\section{BIBLIOGRAPHY}

The following references are arranged alphabetically by author. The titles of papers are given as they appear in the source material; the abstracts are largely composed of sentences excerpted from the material. In some cases these sentences identify specific commercial materials or apparatus. These identifications have not been deleted as they may constitute useful information for the work referenced. As no part of this work was carried out by the National Bureau of Standards, and hence the Bureau performed no evaluations of the identified materials and apparatus, in no case does identification imply recommendation or endorsement, nor is any statement implied concerning the suitability of identified items for any purpose.

A tabular guide precedes the references, and lists the subject matter or measurands, the measuring process, the measurement methods or transducers employed, and other comments including identification of where the work was carried out. Entries in the guide are grouped into 13 Measurand or Subject Matter categories as follows: control, dimension, drilling, force (including torque), machinability, machine-tool technology, power, telemetering, temperature, tool life, tool wear, vibration, and wear land. Arrangement of entries within a category is arbitrary. Entries representing references discussing more than one subject or measurand as a principal topic appear in each applicable category. Secondary topics, including topics of peripheral interest to the bibliography (such as chatter), are identified in parentheses in the Measurand or Subject Matter column. 


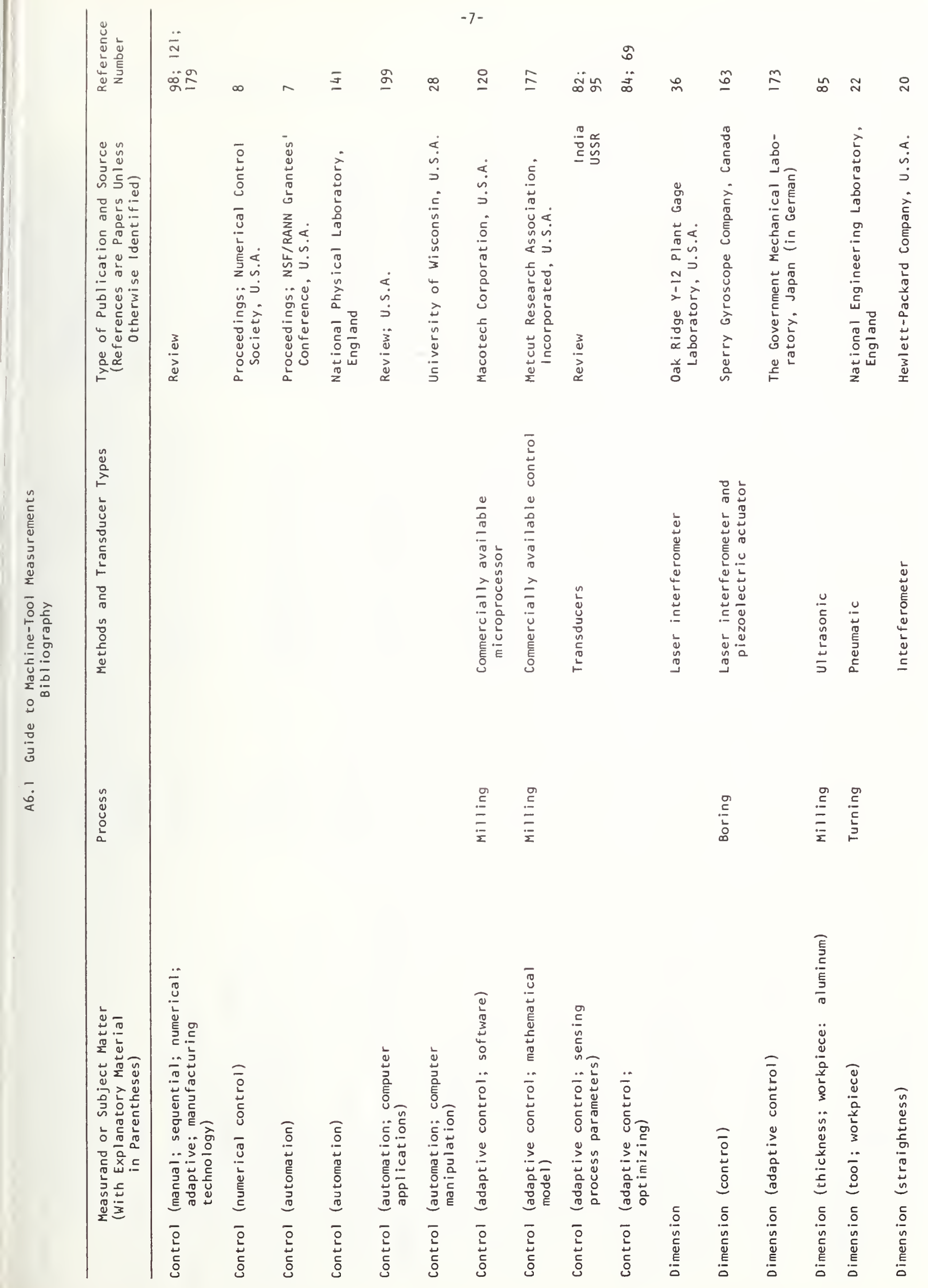




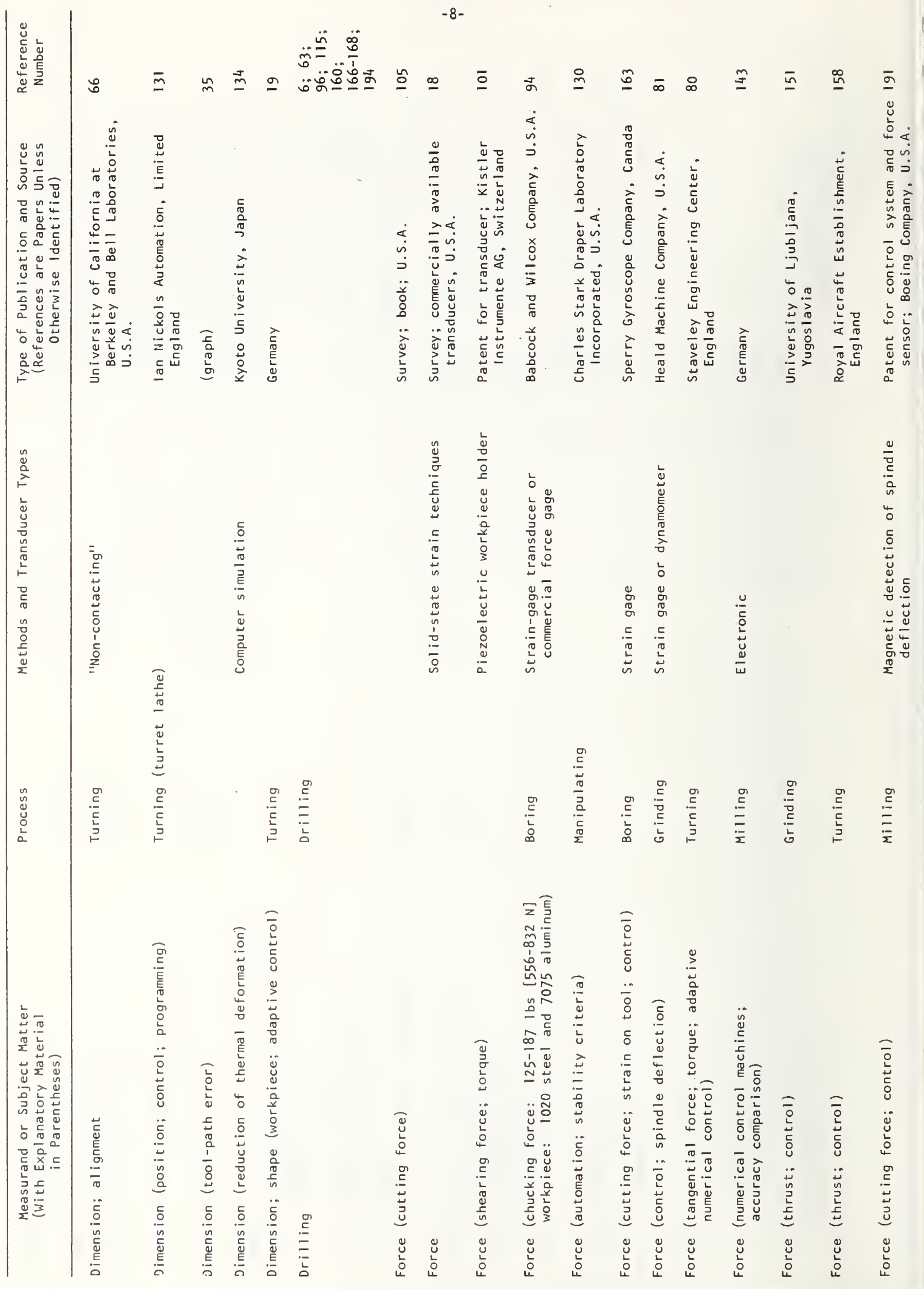




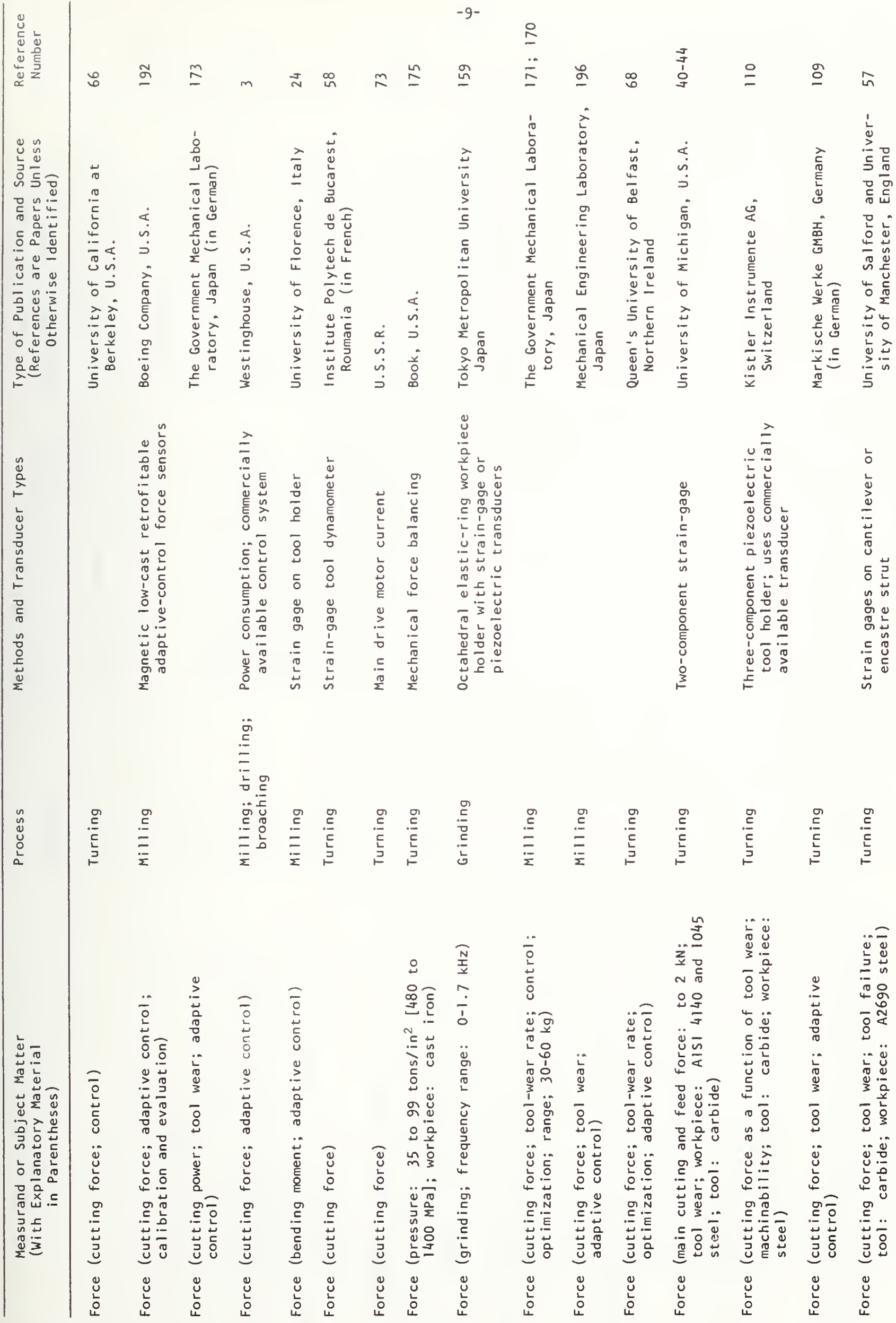




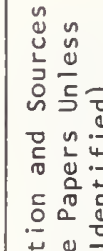

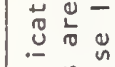

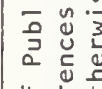

金这苔

范㟧

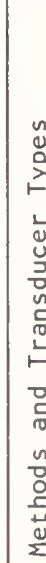

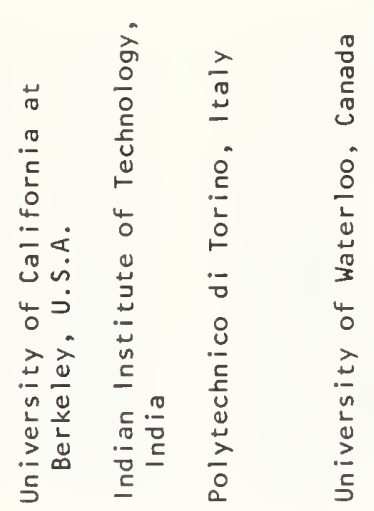

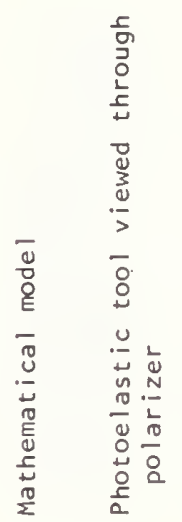

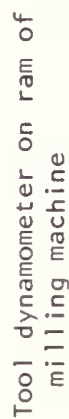

ธิ

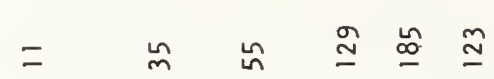

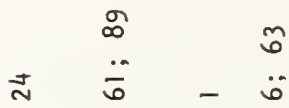

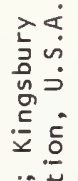

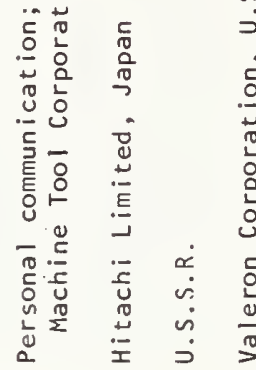

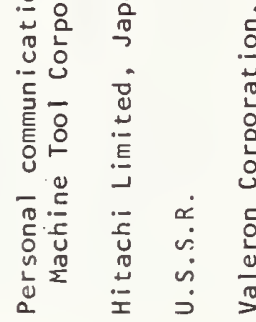

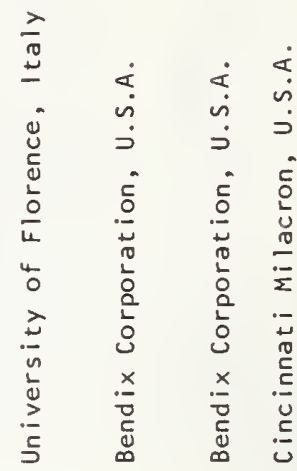

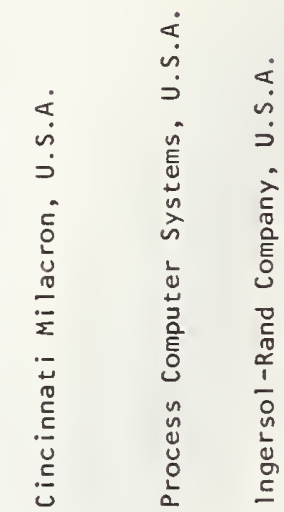

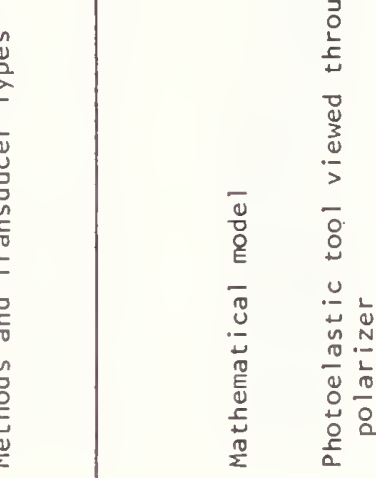

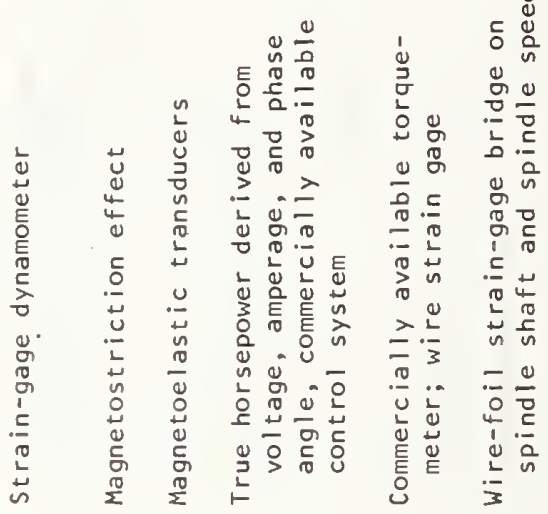

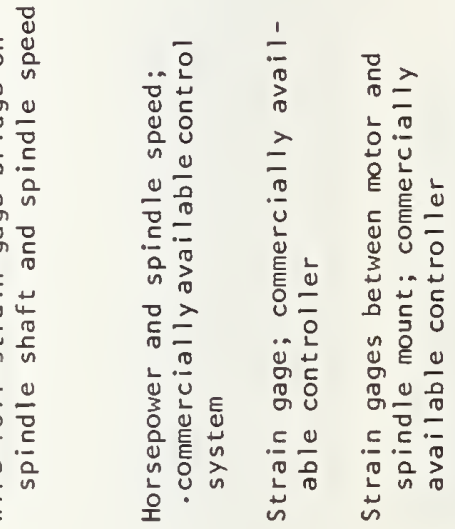

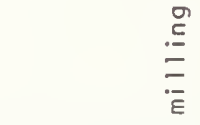

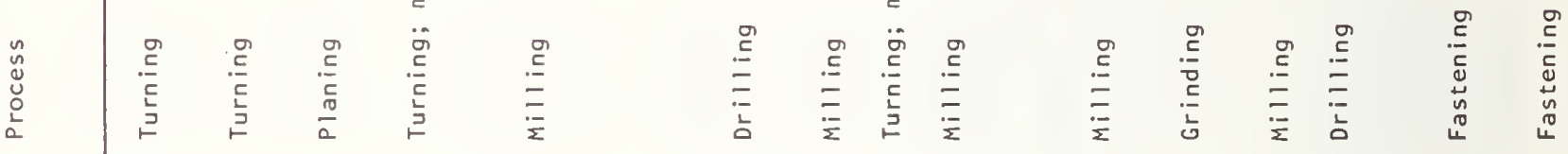

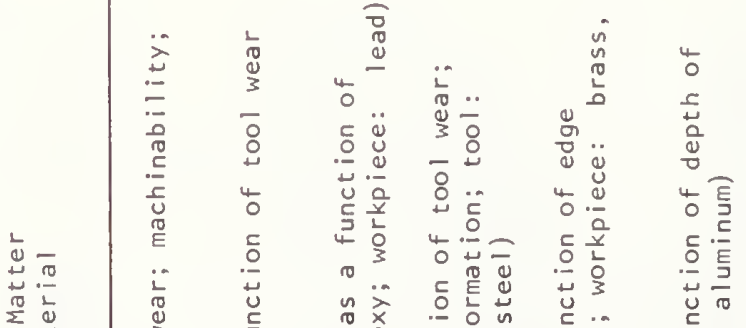

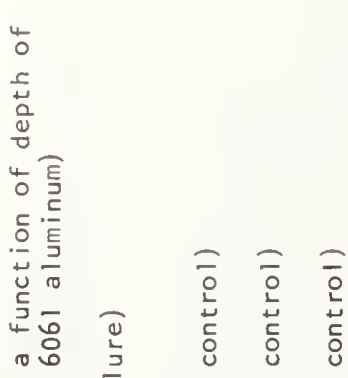

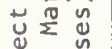

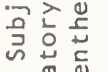

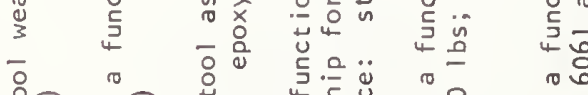

ㅎํำ

$\therefore \frac{\pi}{8}$

$\ddot{\bar{x}} \frac{0}{a}$

ก을

ก

$\stackrel{4}{2} \stackrel{0}{ \pm} \stackrel{0}{ \pm}$

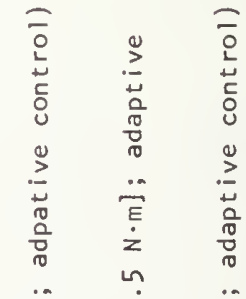

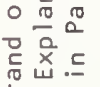

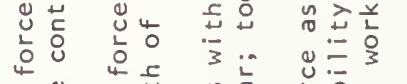

온.

嵌

$\begin{array}{lll}0 & 0 & 0 \\ 0 & 0 & 0 \\ 0 & 0 & 0 \\ 0 & 0 & 0 \\ 0 & 0 & 0 \\ 0 & 0 & 0 \\ 0 & 0 & 0\end{array}$

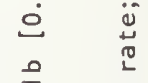

空 上

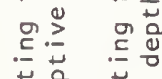

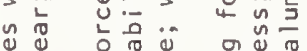

足草

$\frac{5}{0}$

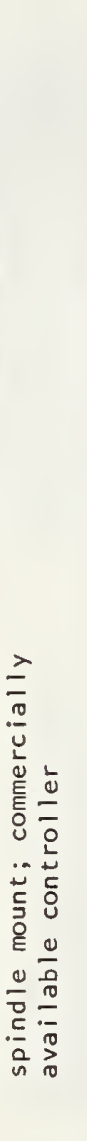




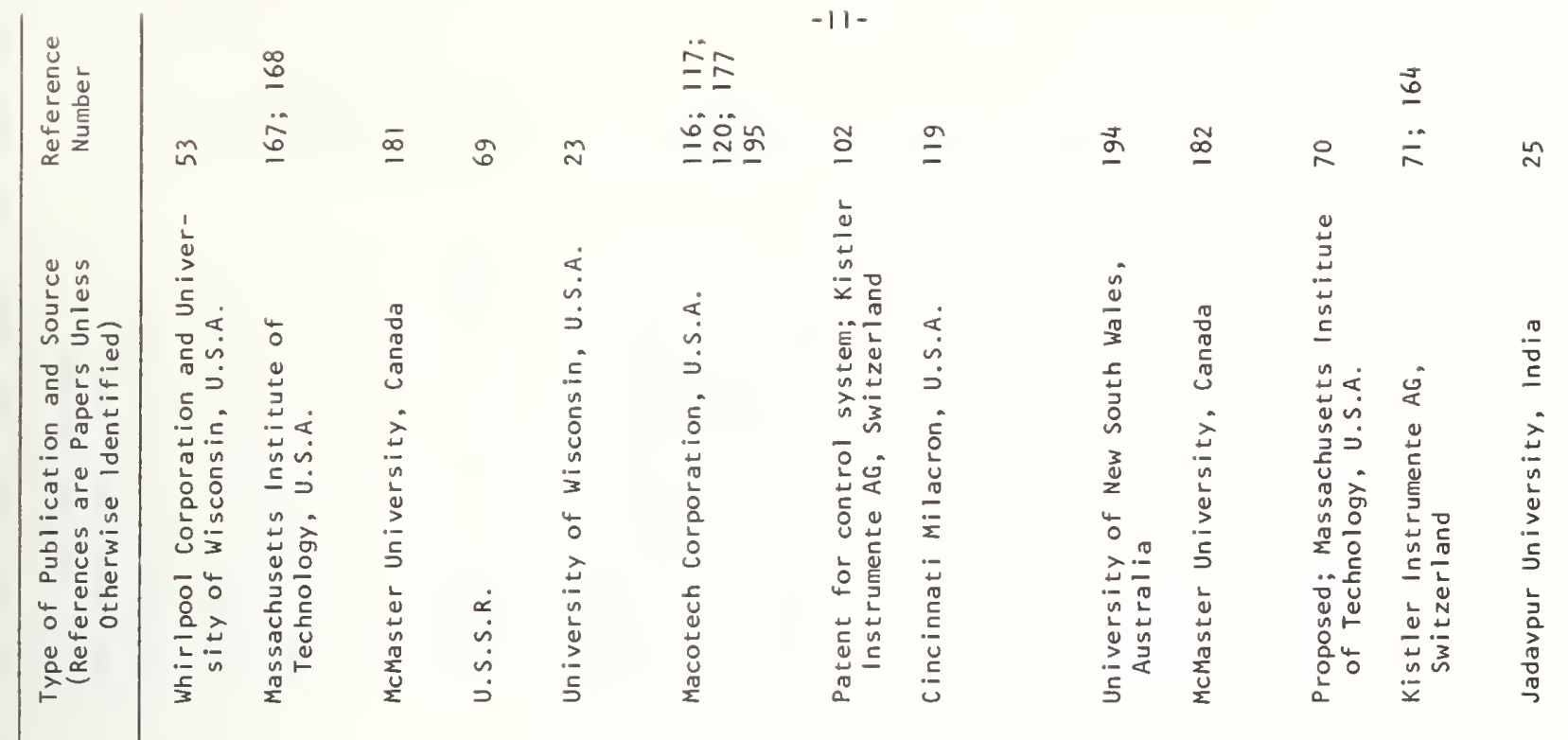

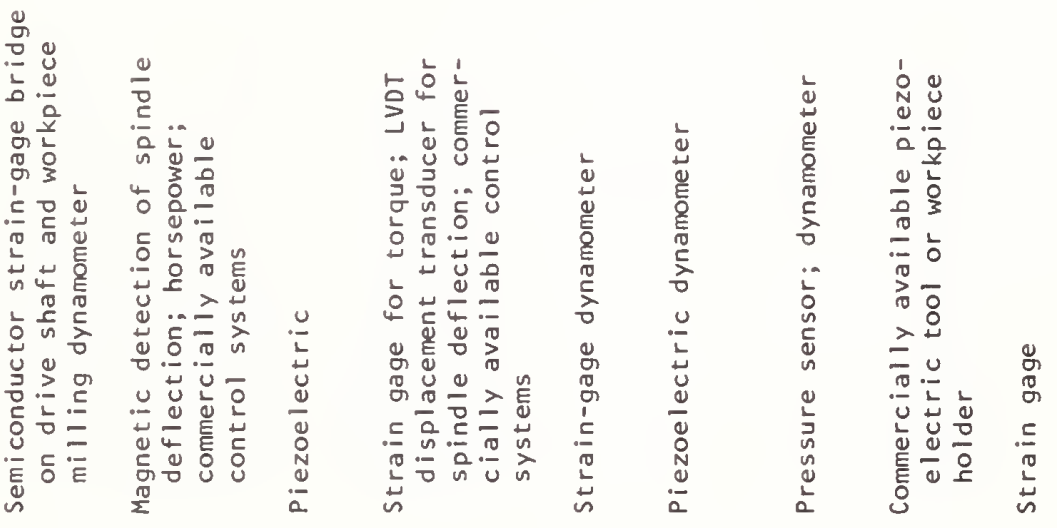

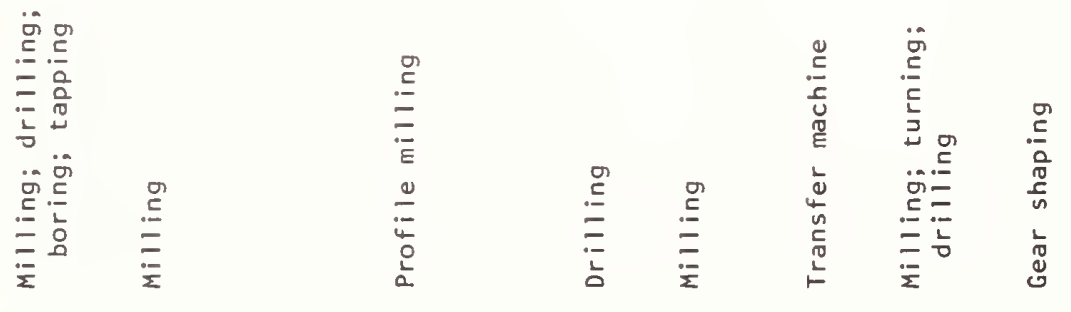

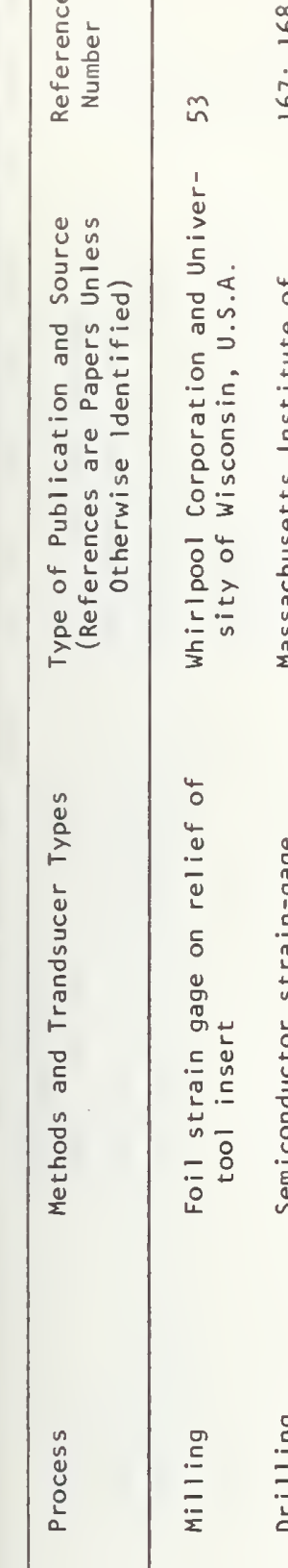




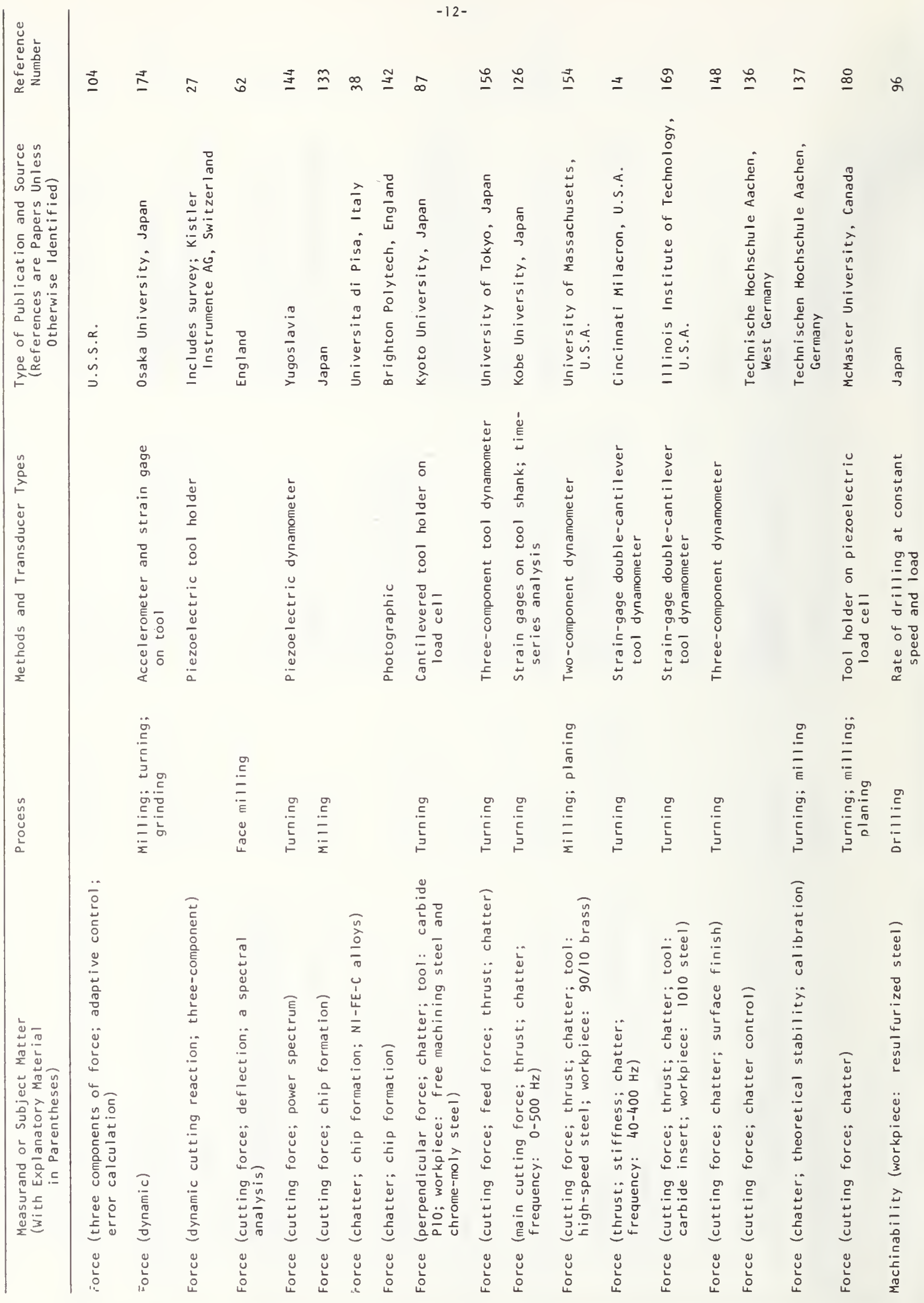




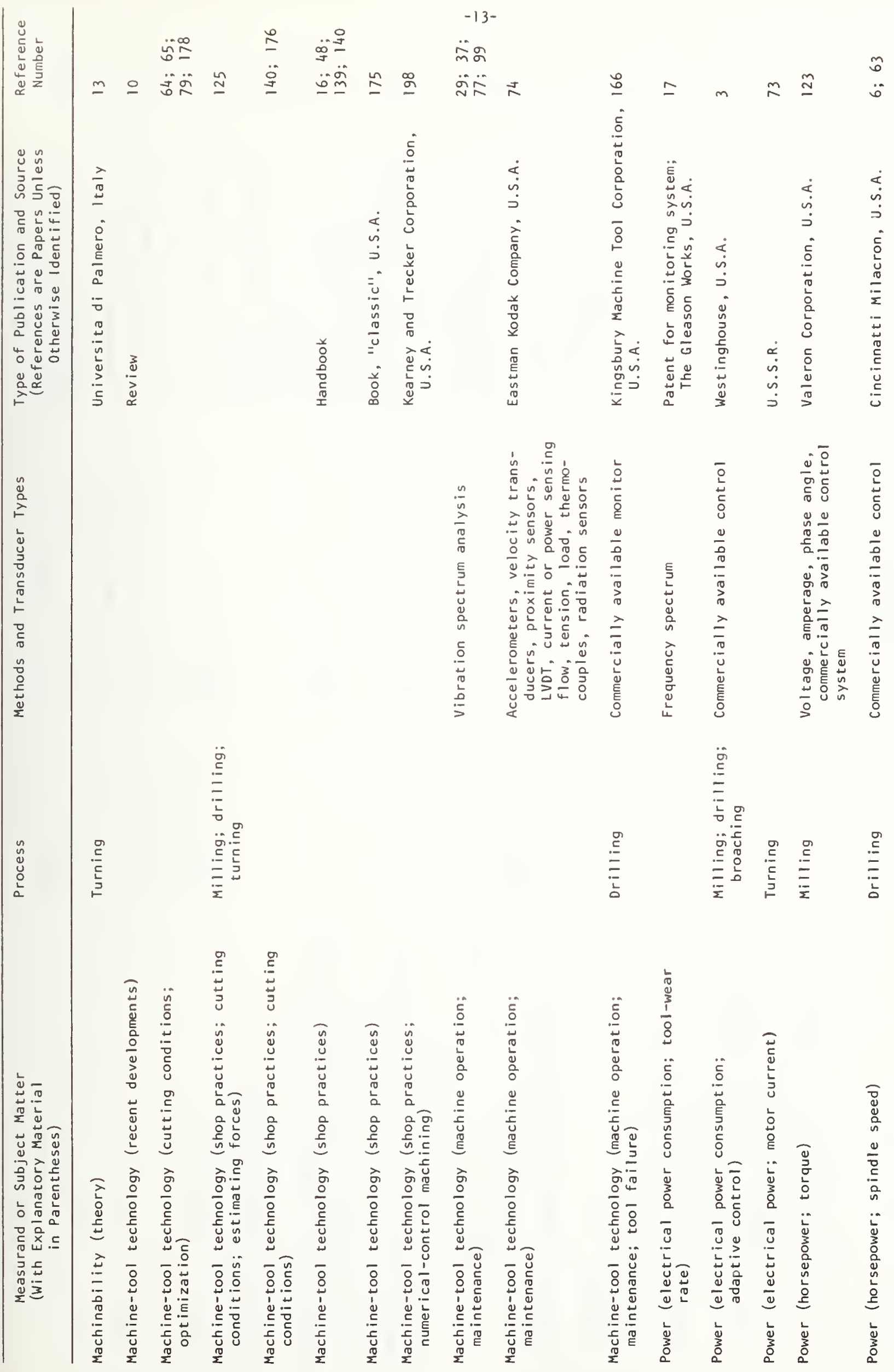


:

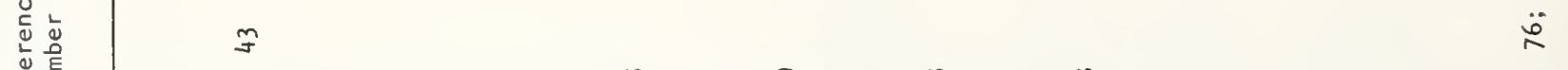

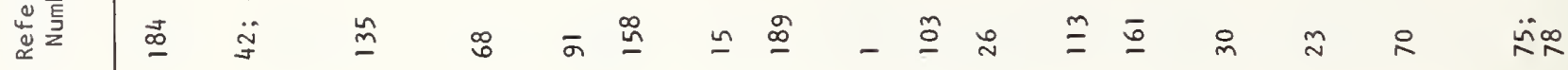

\& $n$

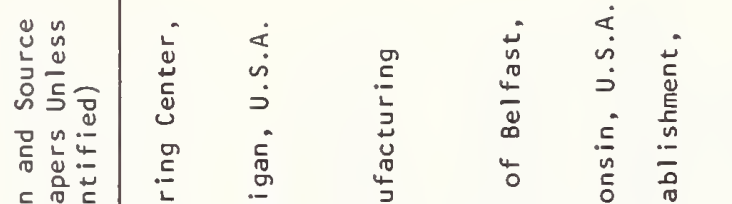

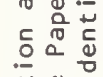

$\stackrel{0}{0} \underset{0}{0}$

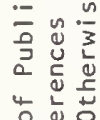

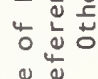

离离

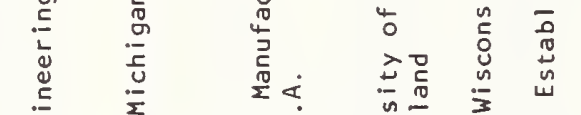

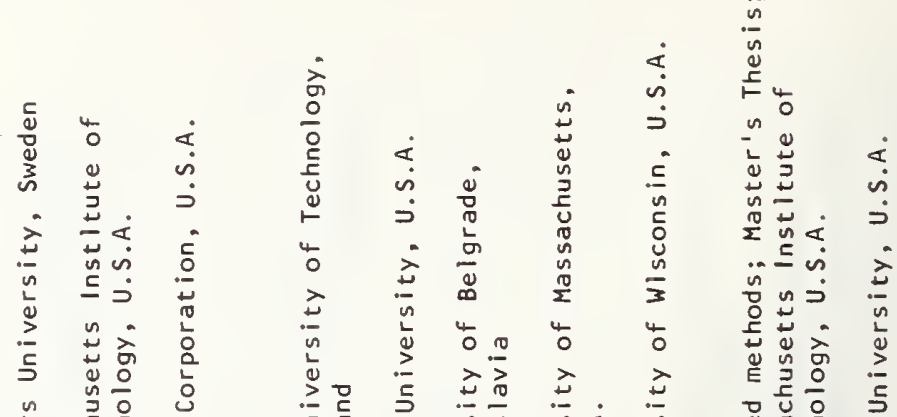

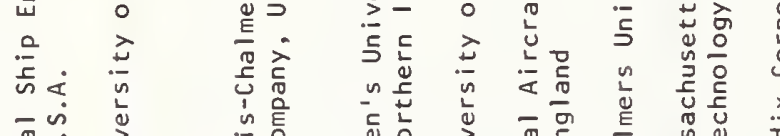

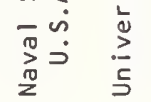

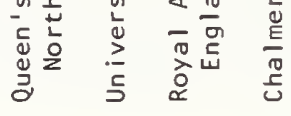

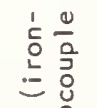

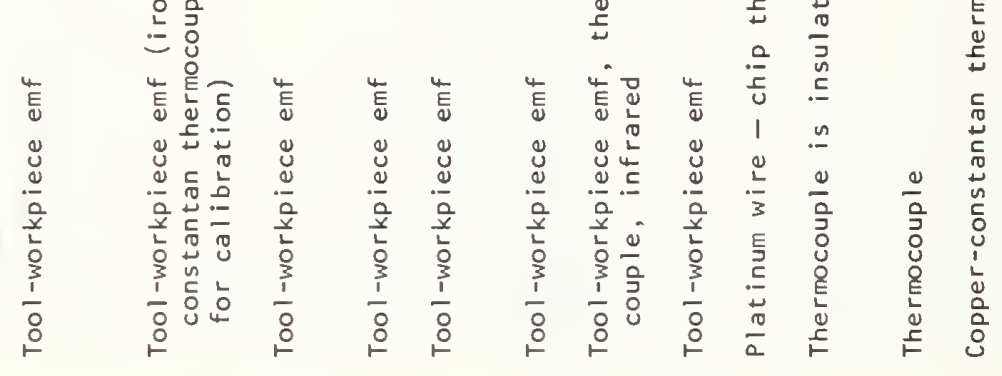

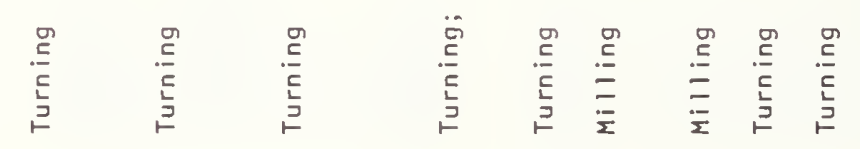

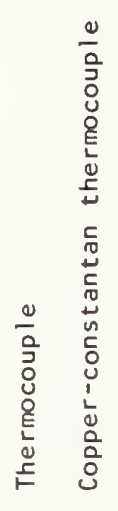

$\stackrel{\text { 昂 }}{\overline{\bar{E}}}$

号

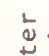

$\stackrel{0}{\frac{\pi}{2}} \cdot \frac{\pi}{4}$

㟧茎岛

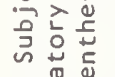

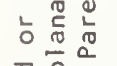

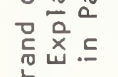

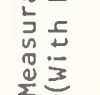

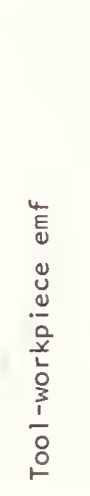
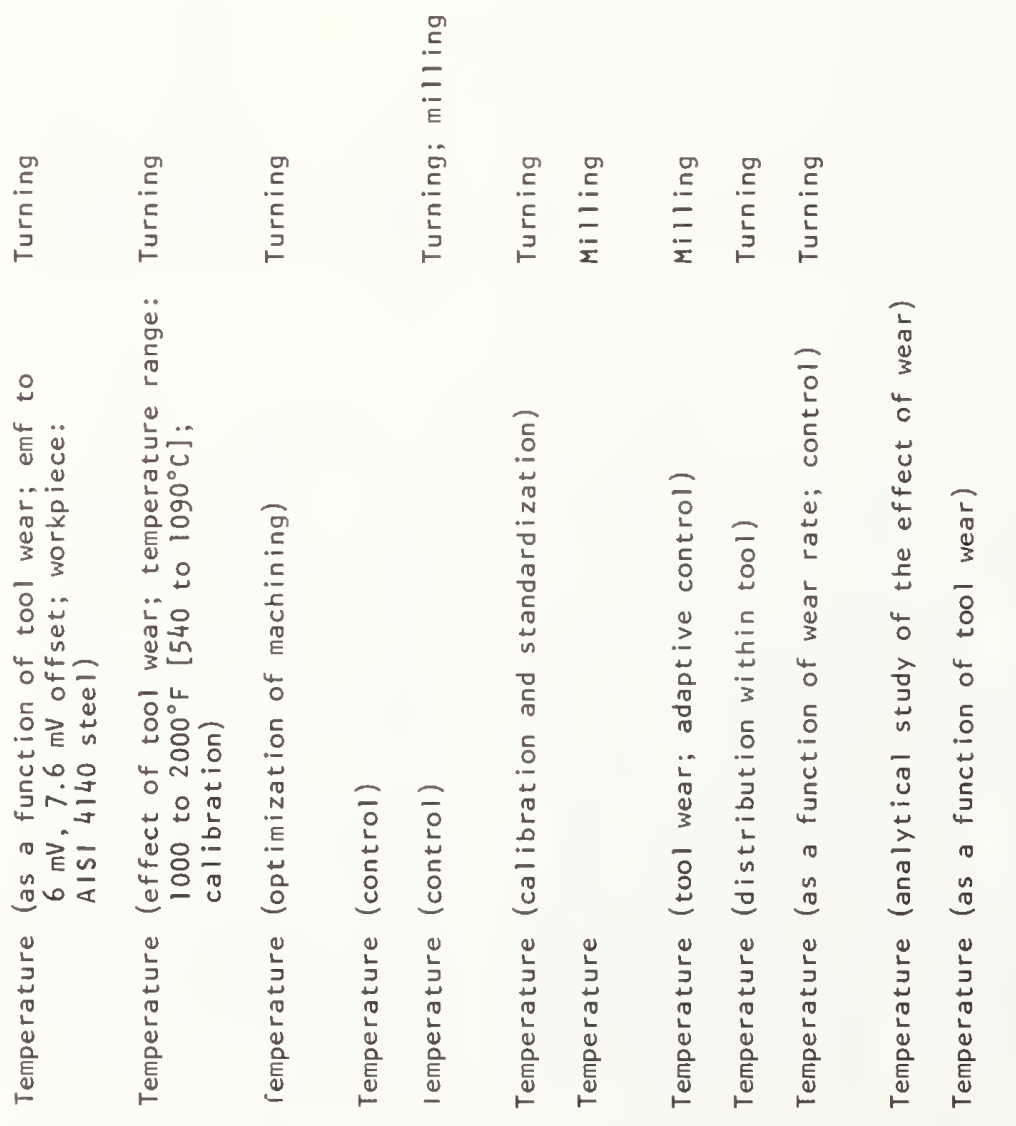

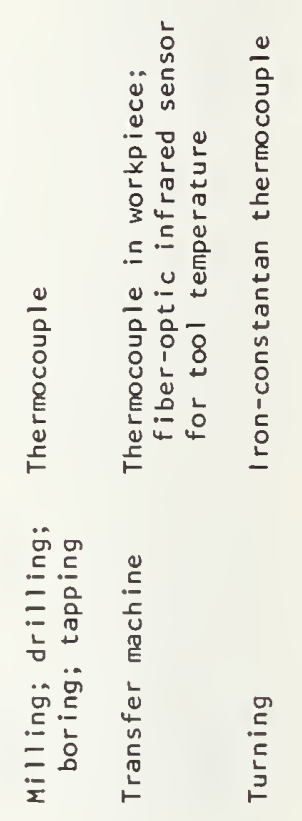




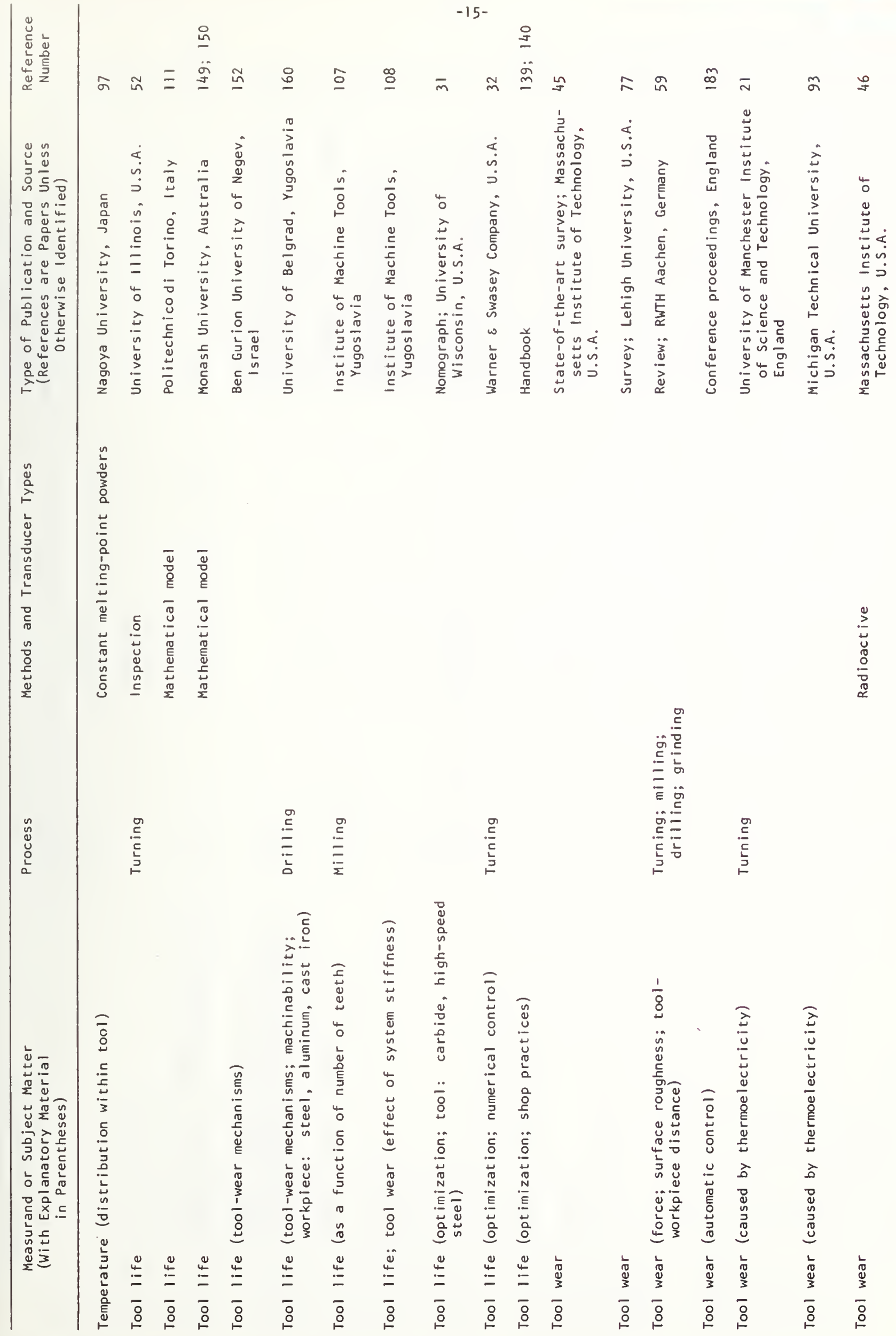




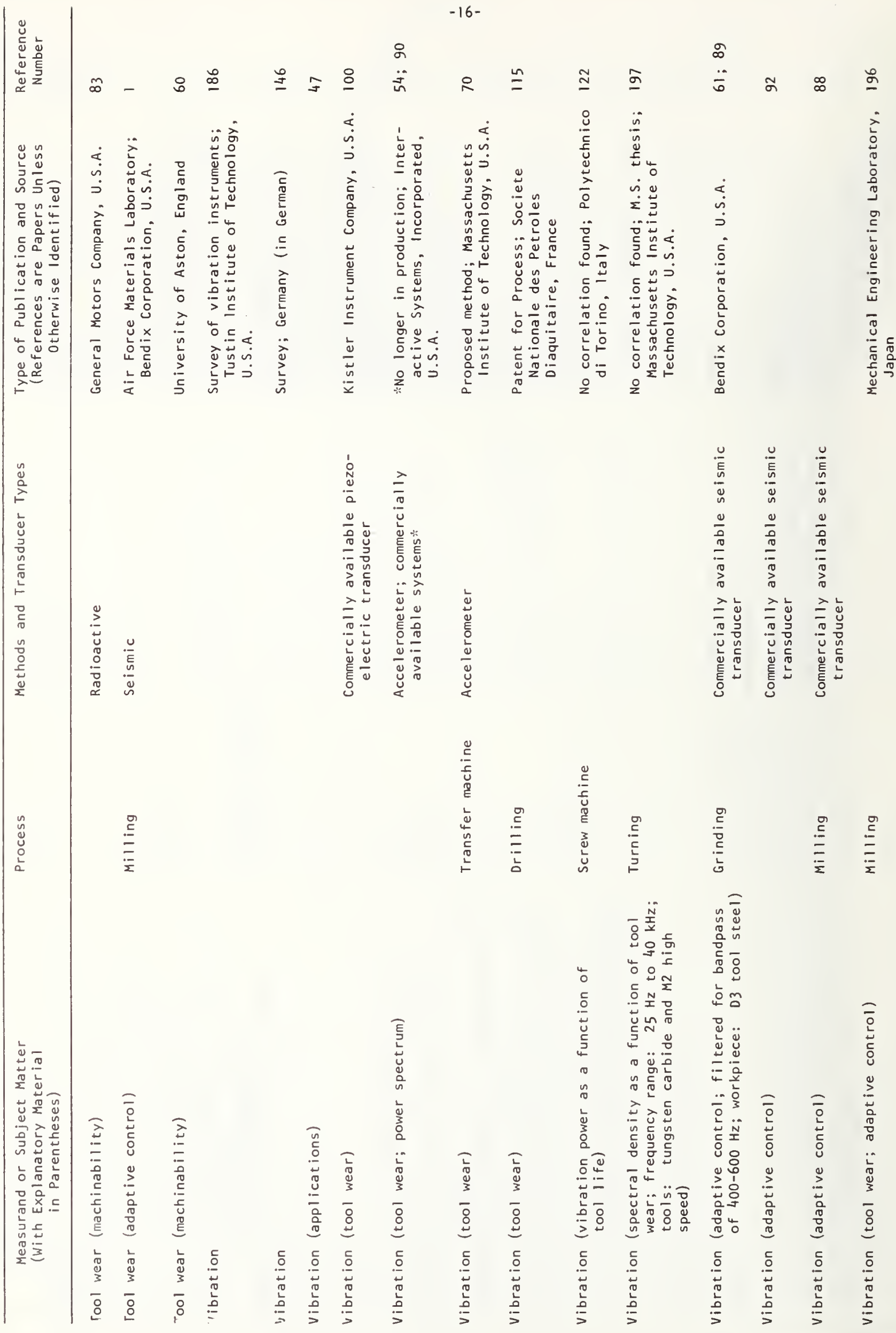





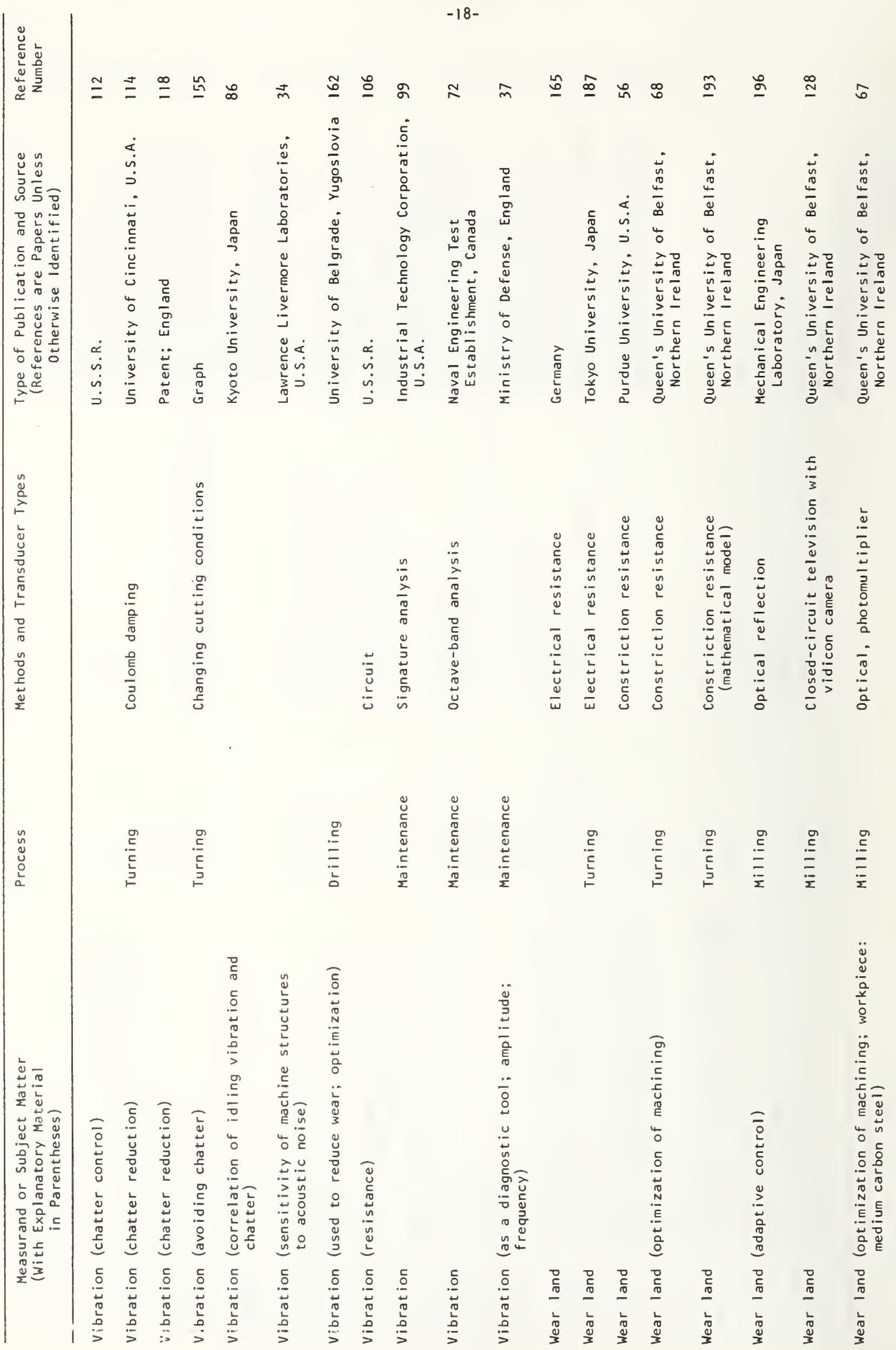


1. Final Report on Development of Adaptive Control Techniques for NumericallyControlled Milling Machines, Air Force Materials Laboratory Report, ML-TDR64-279 (August 1964) and AFML-TR-68-265 (September 1968).

An extensive research program is described in which an equation was developed for flank wear rate as a function of metal removal rate, toolchip thermocouple output, and rate of change of torque.

2. Dynamic Torque Measurement: A QC Boost, Manu. Eng. Manage. 68, No. 3, 29 (March 1972).

An electronic torque assurance system provides laboratory accuracy on the production floor. Its promise: to upgrade reliability of assembly line fastening operations. Torque tensions of $85 \pm 5 \mathrm{ft} \cdot 1 \mathrm{~b}(115 \pm 7 \mathrm{~N} \cdot \mathrm{m})$ are required for 3/4-in hex-head bolts. The system may be extended to crankshaft boring stations. (Used in Chrysler's Trenton engine plant.)

3. Adaptive Control May Be An Answer, Production, No. 3, 72 (1973).

Feed rate is varied in accordance with power consumption or cutting force. System has been fitted to milling machines, deep-drilling machines, or broaching machines.

4. Probleme Bei Der Beurteilung Des Dynamischen Verhaltens Spanender Werkzeugmaschinen (Problems Involved in the Assessment of the Dynamic Behavior of Metal-Cutting Machine Tools), Ind.-Anz. 96, No. 78, 17991805 (September 20, 1974).

An approach is proposed for the determination of the dynamic behavior of metal-cutting machine tools based on dynamic resilience measurements. 12 refs. In German.

5. Microprocessors Turn to Torque Monitoring, Instrum. Contr. Syst. 47, 30 (October 1974).

A d-c strain-gage transducer on the torque tool sends a low level voltage, which is related to the actual torque characteristics of each fastening operation, back to its associated torque controller module via a shielded cable.

6. Torque-Controlled Drilling, Manu. Eng. Manage. 74, 26-27 (May 1975). Cincinnati Milacron has developed a continuous monitoring control system that automatically lowers the feedrate whenever torque on the tool reaches a preset limit, or motor power exceeds the rated amount.

7. Proc. Third NSF/RANN Grantees' Conference on Production Research and Industrial Automation, Cleveland, Ohio, October 28-29, 1975, NSF-RA-T75-036, (National Science Foundation, Wash., D.C., 1975).

8. NC/CAM - The New Industrial Revolution, Proc. of the Thirteenth Annual Meeting and Technical Conference, Cincinnati, Ohio, March 28-31, 1976 (Numerical Control Society, Inc., Glenview, 111., 1976).

9. Cutting Forces Determine Wear on Lathe Tools, Iron Age 217, No. 14, 41-42 (April 5, 1976).

Tool life is governed by flank wear and by cratering at low and high cutting speeds, respectively. Adaptive control of lathe operations uses 
cutting force (continuously determined using electronic circuitry and fed into a process computer) as an indirect measure of tool wear. To determine machinability of a material, measurement of cutting force is preferred to the method of increasing cutting speed to the rate that causes flank failure.

10. Machine Tools Embrace New Technology, Mach. Des. 48, No. 19, 70-77 (August 26, 1976).

Today's machire tool - with new controls, new drives, and a dash of space-age electronics - is quite different from yesterday's product.

11. Abdelmoneim, M. Es., and Scrutton, R. F., Tool Edge Roundness and Stable Build-Up Formation in Finish Machining, J. Eng. Ind., Trans. ASME 96 , 1258-1267 (November 1974).

The results of cutting-force measurements during machining without a sizable unstable build-up edge are compared with results of a theoretical analysis. Tools were mounted individually in a lathe-tool dynamometer which was secured to the ram of a milling machine.

12. Akgerman, N., and Frisch, J., The Use of a Cutting Force Spectrum for Tool Wear Compensation During Turning, Proc. 12th Int. Mach. Tool Des. Res. Conf., Manchester, Engl., September 15-17, 1971, pp. 1-9 (MacMillan and Co., Ltd., Lond., Engl., 1972).

A model is developed relating the reduction of rake face area as a tool wears to cutting force. Cutting forces are measured continuously. A linear relation was found to exist between the cutting force and the depth of cut.

13. Alberti, N., Noto La Diega, S., and Passannanti, A., Some Observations on Metal Cutting with Reference to the Mechanical Characteristics of WorkPiece Materials, Ann. CIRP 20, No. 1, 15-16 (1971).

It is possible to obtain theoretical results more closely related to experimental data, if the mechanical properties of the materials are interpreted unconventionally.

14. Albrecht, P., Dynamics of the Metal-Cutting Process, J. Eng. Ind., Trans. ASME 87, 429-441 (November 1965).

$\overline{A n}$ experimental setup has been built featuring a special design of a tool dynamometer particularly suitable for the measurement of dynamic response of the cutting forces. A cutting tool is activated by a hydraulic shaker. The tool dynamometer, a double cantilever, carrying tension-compression strain gages, has a right-angle knee. The cutting edge is located at the knee of the cantilever while the cutting tool is attached to the end of the cantilever.

15. Alvelid, B., Cutting Temperature Thermo-Electrical Measurements, Ann. CIRP 18, 547-554 (1970).

The objective is to work out a plan for good, standardizable equipment for measuring cutting temperatures. Development of the equipment, which is based on the workpiece-tool thermocouple method is described.

16. Metals Handbook, 8th Edition, Volume 3: Machining, American Society for Metals, Metals Park, Ohio (1972). 
17. Auble, R. E., and Kimmet, G. J., Method and Apparatus for Monitoring Condition of Cutting Blades, U.S. Patent No. 3, 809, 820 (1974).

The power consumption of the drive motor is monitored, and a frequency spectrum of the monitored power consumption is obtained. Power-consumption frequency spectrum is integrated to obtain wear-rate index value, which is compared with previous wear-rate index value.

18. Bailey, S. J., Solid-State Strain Techniques Help Put Force Measurement On-Line, Contr. Eng. 22, 26-29 (June 1975).

The article briefly lays the groundwork for understanding the concept of force and then examines some of the related instrument trends that emerge in today's marketplace. About a dozen commercially available transducers are described briefly.

19. Bake, D., et al., Development of New Sensors for Geometrical A-C Systems for Lathes, Z. Wirschaft. Fertigung, No. 1, 68 (1973).

The development of measuring devices for gaging workpiece dimensions and shapes is described.

20. Baldwin, R., Inspecting Machine Tool Geometry Interferometrically, ElectroOpt. Syst. Des., 36-39 (October 1976).

With automation, dimensional accuracy of machined parts has become increasingly dependent on the geometry of the machine that produced them. A straightness interferometer using small optical flats to measure straightness over a long travel is discussed.

21. Barrow, G., and Spencer, R. M., Some Factors Influencing the Reliability of Tool Life Tests, Ann. CIRP 18, 199-206 (1970).

Techniques for determining the effect on thermoelectric tool wear of variations in headstock and tailstock resistance are described. The results obtained indicate that the large variations in tool life obtained cannot be attributed solely to thermoelectric tool wear. It is suggested that differences in the dynamic characteristics of the lathes used have considerable influence on tool life.

22. Bath, M., and Sharp, R., In-Process Control of Lathe Improves Accuracy and Productivity, (Proc. 9th Int. Mach. Tool Des. Res. Conf., Birmingham, Engl., September 1968), Book, Advances in Machine Tool Design and Research 1968, pp. 1209-1221 (Pergamon Press Inc., Elmsford, N.Y., 1969).

Dimensional accuracy of a lathe workpiece is improved by monitoring errors that arise from tool wear, machine misalignment, workpiece deflection, and tool settings. Pneumatic gages with pressure and displacement transducers are used. Tool wear is monitored by a gage placed close to the tool, measuring the distance between the tool post and the workpiece surface. A feedback control system is used to correct the errors either continuously or in steps.

23. Beadle, B. R., and Bollinger, J. G., Computer Adaptive Control of a Machine Tool, Ann. CIRP 19, 61-65 (1971).

A method of investigating various techniques of adaptively controlling the metal removal process is presented. The method uses a hybrid computer

for data collection and machine tool control. Spindle torque is measured by a semiconductor strain-gage bridge on the drive shaft; spindle speed is measured by a variable reluctance pick-up 
mounted near a drive gear; cutter forces are measured along three axes by a milling dynamometer on which the workpiece is mounted; and tool temperature is sensed by a thermocouple and telemetered by an FM transmitter.

24. Bedini, R., Lisini, G. G., and Pinotti, P. C., Experiments on Adaptive Control of a Milling Machine, J. Eng. Ind., Trans. ASME 98, No. I, 239-245 (February 1976).

The machine tool employed is an 01 ivetti NC machining center provided with a CNZ control unit. The bending moment acting on the cutter was measured using a wire strain-gage bridge mounted on the tool holder. The torque measurement was performed using a Vibrometer TG 10 torquemeter mounted on the shaft of the $d-c$ spindle motor.

25. Bhattacharyya, A., and Dev, S. R., Forces During the Process of GearShaping, Ann. CIRP 20, No. 1, 33-34 (1971).

An A-6 type FeTlows Gear Shaper has been used. All blank materials were cast iron having an average hardness of $160 \mathrm{HB}$. All cutters were of high-speed steel. A specially built dynamometer uses six strain gages, two each to measure axially-downward power component, radial force component, and the tangential force component.

26. Billett, R. A., Studies of Cutting Temperature Control Applied to A Lathe Spindle Speed, (Proc. 9th Int. Mach. Tool Des. Res. Conf., Birmingham, Engl., September 1968), Book, Advances in Machine Tool Design and Research 1968, pp. 1273-1287 (Pergamon Press Inc., Elmsford, N.Y., 1969).

The wear rate of tools is related to temperature at the tool-work interface. Cutting speed is varied so as to maintain constant cutting temperature and hence constant tool-wear rate. Temperature is measured using a thermocouple in the insulated tool. Thermal EFM is also used as an index of machinability and of the cooling property of the cutting fluid.

27. Blankenstein, Dr. 1. B., Development of a 3-Component Cutting-Reaction Meter, Ind. Anz. 85. Ausgabe "Werkzeugmaschine und Fertigun-Stechnik," Teil 1: Spangebende Formung, Verlog W. Girardet, Essen (October 22, 1968). (Translation 20-055E, Kistler Instrumente AG, Switz.).

Describes the development and function of a 3 -component cuttingreaction meter with piezoelectric measuring transducers. Includes chart of known existing cutting-reaction meters suitable for dynamic investigations. 27 refs.

28. Bollinger, J. G., Computer Control of Machine Tools, Ann. CIRP 21 , No. 2, 215-218 (1972).

The intent of this paper is to focus on the problem of actual manipulation of machinery by the computer and to illustrate how the potential for direct computer manipulation of machine tools is growing and the factors that will influence its future impact.

29. Bollinger, J.G., and Ewald, D. L., Spectral Analysis of Modulation Phenomena for Determining Physical Behavior, Proc. 2nd N. Amer. Metalwork Res. Conf., Madison, Wisconsin, May 20-22, 1974, pp. 666-681 (Society of Manufacturing Engineers, Dearborn, Mich., 1974). 
The use of spectral analysis of a wide variety of transduced signals is finding extensive application in manufacturing. The monitoring of tool-wear conditions, identification of failure modes of tools and machinery, and the analysis of process states are all examples of current applications. The objective of this paper is to outline the analytical nature of these modulation principles and to relate various modulation forms to the graphical output of typical spectrum analyzers.

30. Boothroyd, G., Eagle, J. M., and Chisholm, A. W. J., Effect of Tool Flank Wear on the Temperatures Generated During Metal Cutting (Proc. 8th Int. Mach. Tool Des. Res. Conf., Manchester, Engl., September 1967), Book, Advances in Machine Tool Design and Research 1967, pp. 667-680 (Pergamon Press Inc., Elmsford, N.Y., 1968).

31. Boothroyd, G., and Rusek, P., Maximum Rate of Profit Criteria in Machining, J. Eng. Ind., Trans. ASME 98, 217-220 (February 1976).

In the present paper it is shown that a condition can be determined in which the profit obtained within a given period is maximized and that this can be used as a single criterion replacing those previously employed; this condition will be referred to as maximum efficiency. Nomographs are given for optimum tool-life equations for carbides and high-speed steel.

32. Bott, J. C., Expert Opinion - Don't Baby NC Turning Machines, Automation, 85-86 (September 1975).

Neglect of the fundamentals of good machining practice and failure to prepare properly for NC turning are most significant causes of low machine-tool productivity.

33. Braun, S., Fast Dynamic Tests for On-Line Measurements on Machine Tools, Ann. CIRP 22, No. 1, 113-114 (1973).

Methods for extracting dynamic data outlined in this paper are aimed at overcoming two types of empirical difficulty encountered if the actual cutting forces during machining are used as system inputs: (1) the requirement for relatively long averaging times to permit stabilization of computed results and (2) the complexity of analysis resulting from motion between machine-tool members that are ideally fixed relative to each other. The methods include use of a pseudorandom test signal, signal extraction by time-domain averaging, and prefiltering.

34. Bryan, J., Brooks, H., Lamb, J., and Willett, G., Influence of Airborne Noise on the Structures of Precision Machine Tools and Gaging, SME Tech. Paper MR74-936 (Society of Manufacturing Engineers, Dearborn, Mich., 1974).

Results of tests on the sensitivity of a diamond turning machine and a Talystep surface finish analyzer to acoustic vibration are presented. Resonant peaks of vibration greater than $4 \mu$ in $(0.1 \mu \mathrm{m})$ peak-to-valley were observed between the turning-machine tool post and spindle at moderate sound levels. 
35. Burnham, M. W., True Tool Path Considerations, SME Tech. Paper MR76-901 (Society of Manufacturing Engineers, Dearborn, Mich., 1976).

Some sources of error in the true tool path during cutting are discussed using 6061 aluminum as an example. An analysis of the relative stiffness of various components in the cutting process results in a graph predicting the tool path error. Methods available for calculating the influence of the cutting forces and the part-machine stiffnesses are described. Experimental approaches to assessing the relation between cutting force and depth of cut are also given.

36. Burrus, B. M., Applications of the Dimensional-Measuring Laser Interferometer in the Oak Ridge Y-12 Plant Gage Laboratory, prepared for the U.S. Energy Research and Development Administration under U.S. Government Contract $W-7405$ ENG 26.

The report describes and illustrates some applications of the dimensional-measuring laser interferometer in use in the $Y-12$ Plant for several years. Illustrations of on-the-job applications are presented.

37. Carmody, T., Measurement of Vibration as a Diagnostic Tool, Trans. Inst. Mar. Eng. 94, Pt. 6, 147-159 (1972).

The technique makes use of the fact that all rotating machines vibrate to some degree or other. Two parameters of vibration are normally used for diagnostic work: the amplitude (i.e., displacement velocity or acceleration of the element being measured) and the frequency at which it occurs, the amplitude of vibration giving an indication of the machine's condition and the frequency at which it occurs, identifying its probable source. Although vibration monitoring of machinery is.a relatively new technique, it is potentially one of the most cost-effective of the various nondestructive test techniques at present available.

38. Cao, G. C., Cutting Phenomena Interpretation in Machine-Workpiece-Tool System, Ann. CIRP 20, No. 1, 25-26 (1971).

This study is the fourth stage of research work on the analysis of phenomena which appear in chip formation. Experimental quick-stop tests on $\mathrm{Ni}-\mathrm{Fe}-\mathrm{C}$ alloys were performed to study the influence of the cutting parameters on the formation of the chip. A recording of the cutting forces is included.

39. Chandrasekaran, H., and Hagarajan, R., Influence of Flank Wear on the Stresses in a Cutting Tool, ASME Paper 76-WA/Prod 30 (American Society of Mechanical Engineers, N.Y., N.Y., 1976).

The experimental procedure included using a photoelastic tool (epoxy resin) to machine a soft metal (lead). The whole setup was interposed between the polarizer and analyzer of a photoelastic bench. ( 28 references.) Experimental detail is described in a paper by S. R. Venkatesan and H. Chandrasekaran. (Reference 188.)

40. Colwell, L. V., Methods for Sensing Rate of Tool Wear, Ann. CIRP 19, 647-651 (1971).

Changes in the magnitude, ratio, and phase difference of machining force components are due to flank wear, rounding of cutting edge, workpiece rigidity, and coolant effectiveness. Hence, suitable force sensors with rapid-response circuitry can be used to provide an indication of wear. 
41. Colwell, L. V., Tracking Tool Deterioration by Computer (During Actual Machining), Ann. CIRP 23, No. 1, 29-30 (1974).

Measurements of cutting force components are used to monitor tool wear. A force ratio of the cutting force components in a turning operation was designated as a measure of tool dullness during the starting and dwell phases of cutting and at various depths of cut.

42. Colwel1, L. V., Cutting Temperature Versus Tool Wear, Ann. CIRP $\underline{24}$, No. 1, 73 (1975).

Cutting forces and temperatures are sensed during turning cuts on a numerically controlled lathe. Force sensing is accomplished with a two-component, strain-gage dynamometer which provides analog signals for the feeding component, Fn, and the power component, Fc, as measured in the direction of cutting velocity. A tool-work thermocouple senses temperature.

43. Colwell, L. V., Progress Report on Temperature Sensing, Diagnostics Sensing in Machining Operations, Project \#320357 (University of Michigan, Ann Arbor, Mich., April 1975).

Deterioration during machining was monitored by measuring temperature and force. It was found that cutting temperature, measured by the toolwork thermocouple method, can provide a sensitive indication of tool wear. Both cutting temperature and forces change significantly for changing thickness of cut and the gage dynamometer.

44. Colwell, L. V., Mazur, J. C., and Angell, J., Progress Report, Diagnostic Sensing in Machining Operations, Project \#320357 (University of Michigan, Ann Arbor, Mich., May 1975).

Cutting force components and their ratios are used as a measure of tool dullness. Other potentially useful information contained in cutting force signals is: 1) chip-breaking behavior, 2) crater wear, 3) build-up edge behavior, and 4) seizure on the tool flank.

45. Cook, N. H., Subramanian, K., and Basile, S. A., Survey of the State of Art of Tool Wear Sensing Techniques prepared for the National Science Foundation under Grant G1-5486I (Massachusetts Institute of Technology, Cambridge, Mass., September 1975).

Documents the existing types of tool-wear sensors. The criteria used to define tool life are discussed. Description of past and present RED efforts, patents, and available tool-wear sensing systems are presented. A tool-wear sensing matrix was prepared to establish which physical sensing phenomena have been studied relative to specific cutting processes. An annotated bibliography is included.

46. Cook, N. H., Subramanian, K., and Basile, S. A., Tool Wear Sensors, Third NSF/RANN Grantees' Conf. Prod. Res. Ind. Automation, Cleveland, Ohio, October 28-29, 1975, pp. 23-26 (National Science Foundation, Wash., D.C., 1975).

The method under investigation involves implantation, or production in situ, of a very small radioactive zone within the tool-wear zone. After each cutting cycle the tool's activity is sampled; when the activity drops abruptly tool wear has reached a specific amount or the tool has failed catastrophically. 
47. Corbach, K., Purpose and Application of Vibration Measuring Techniques in Industrial Practice (Proc. 10th Int. Mach. Tool Des. Res. Conf., Manchester, Engl., September 1969), Book, Advances in Machine Tool Design and Research 1969, pp. 379-393 (Pergamon Press Inc., Elmsford, N.Y., 1970).

Because of the fact that dynamic behavior represents the dominant factor in evaluation of a machine tool's capacity, application of data from vibration measuring techniques often may help to increase the efficiency of a machine tool. A few examples are demonstrated to show how several vibration problems may be solved. 9 refs.

48. Automation, Numerical and Computer Control, Chapter 12 of Tool and Manufacturing Engineers Handbook, Daniel B. Dallas, Ed., 3rd Edition (Society of Manufacturing Engineers, Dearborn, Mich., 1976).

This chapter contains 20 references and a bibliography of 21 entries.

49. Defilippi, A., and Ippolito, R., Adaptive Control in Turning: Cutting Forces and Tool Wear Relationships for P10, P20, P30 Carbides, Ann. CIRP 17, 377-385 (1969).

Experiments to investigate the use of cutting forces for tool-wear sensing are carried out. Generally, cutting forces increase with tool wear; however, the increases are very small (in the same range as variations due to other factors such as depth of cut, variations in composition of workpiece, etc.) and dependent on the tool-work combination.

50. Defilippi, A., and Ippolito, R., Evaluation of the Tool Wear in Frontal Milling, Paper presented by G. F. Micheleth at the 19th Annual Assembly Int. Inst. Prod. Eng. Res. (CIRP), Geneva, Switz., September 1976 (Verlay Technischie Rundschau Hallwag, Bern, Switz., 1969).

Some correlation between cutting forces and tool wear was noted.

51. Defilippi, A. and Ippolito, R., Analysis of the Correlation Among: Cutting Force Variation (vs. Time) - Chip Formation Parameters - Machinability, Ann. CIRP 21, No. 1, 29-30 (1972).

Turning tests have been performed on various casts of three different steels. During the cut, main cutting force, fixed force, and, at the end of the test, tool wear were measured. The test was 2 minutes and only feed force increase was considered. It is necessary to have a high cutting speed to obtain a significant cutting force increase.

52. DeVor, R. E., Anderson, D. L., and Zdeblick, W. J., Tool Life Variation and Its Influence on the Development of Tool Life Models, ASME Paper 76-WA/Prod 1 (American Society of Mechanical Engineers, N.Y., N.Y., 1976).

An investigation into the nature of the inherent variation of tool life over a range of cutting conditions for a finish turning process is presented. In this study, tool life is based upon a fixed amount of wear on the clearance face of the tool.

53. Doolan, P., Phadke, M. S., and Wu, S. M., Computer Design of a Minimum Vibration Face Milling Cutter Using an Improved Cutting Force Model, J. Eng. Ind., Trans. ASME 98, 807-810 (August 1976).

A small foil resistance strain gage was mounted on the relief face of the carbide insert. When the cutter was mounted on the machine, the 
plane of the strain gage was nearly parallel to the finished surface and it measured strain on the insert in the direction approximately parallei to the tangential cutting force. A special hollow centering shank drawbar was made through which the strain gage leads are passed to the top of the spindle head. Cutting force was measured under fifteen different cutting conditions.

54. Edwin, A., and Vlach, T., A New Approach to Tool Wear Monitoring, (Proc. 27th Ann. Conf. Instrum. Soc. Amer., N.Y., October 1972), Book, Advances in Instrumentation 27, Paper 72-626 (Instrument Society of America, Pittsburgh, Penn., 1972 ).

The vibration of a cutting head is measured continuously and analyzed by a power spectrum analyzer. Changes in vibration pattern correspond to tool wear. The commercial system developed is comprised of a vibration sensor, analyzer, and a mini-computer. (This system is no longer in production.)

55. Eisengrein, R. H., Personal Communication, Letter to N. H. Cook, K. Subramanian, and S. A. Basile, Massachusetts Institute of Technology, Cambridge, Mass. (July 30,1974 ).

During a drilling operation, torque was sensed using strain-gage type dynamometers. Large peak torques were found superimposed on the tool torque. When the peak torques were $250-300 \%$ of tool torque (the peaks repeated 3 , 4 , or 5 times) tool failure followed. A non-contact type torque sensor is also under investigation.

56. El Gomayel, Y., and Zakaria, A. A., Tool Condition Monitoring for Adaptive Control, SME Paper MR-74-143, April 1974.

Uses the constriction-resistance method for estimating tool wear similar to that developed at the Queen's University of Belfast.

57. Ellis, J., The Failure of Carbide Tools When Machining High Strength Steels, Ann. CIRP 21, No. 1, 25-26 (1972).

Force measurements were made using either a cantilever or encastre strut-type dynamometer with strain gages as the sensing elements. Both force and wear tests were done either pseudo-orthogonally (bar turning with $90 \mathrm{deg}$ approach angle and small nose radius) or orthogonally (radial machining of a disc). Flank wear and artificially ground wear lands were measured on a tool-makers microscope. For accurate predictions of tool failure, more sophisticated methods of calculating stresses are required, together with accurate values for tool material properties.

58. Enache, St., and Stajescu, E., Contribution Concernant l'Establissement Experimental des Forces de Coupe au Tournage, Ann. CIRP 22, Vol. 1, 9-10 (1973).

The dynamometer uses "capteurs resistifs." In French.

59. Essel, K., and Hansel, W., Development of Sensors for Process Control Systems in the Field of Production Engineering, Gesellschaft fur Kerforschung MBH, Karlsruhe, PDV-Report KFK-PDV 41, May 1975.

An account is given of the development of sensors for measuring characteristic values of turning, milling, drilling, and grinding, 
processes, sensors for tool wear, tool-work distances, cutting force components, and surface roughness are represented in detail. Sensor performance is specified.

60. Etheridge, R. A., and Hsu, T. C., The Specific Wear Rate in Cutting Tools and Its Application to the Assessment of Machinability, Ann. CIRP 18, 107-117 (1970).

In this paper a definition of tool wear site is proposed which is applicable to both crater and flank wear. The derivation of this quantity from wear curves is demonstrated and its application to the assessment of machinability is discussed.

61. Feinberg, B., Adaptive Control: Trainability Adds a New Dimension, Manu. Eng. Manage. 67, No. 6, 18-22 (December 1971).

An adaptive system that learns from experience enhances the viability of adaptive process control. Bendix does it by adding a training 1 oo $p$ and on-line nondestructive inspection capability. A surface grinding machine is fitted. with transducers for measuring spindle speed, torque, and vibration.

62. Field, C. F., Colloquim on Engineering Applications of Spectral Analysis, Inst. Elect. Eng. (London, January 1969).

A vertical mill was used and tests were limited to determining the relative deflection of two points on the machine whilst face milling. With a measure of cutting force in the same axis, it was intended to cross-correlate force and deflection and ultimately arrive at an estimation of frequency response. This was expected to provide quantitative information with respect to resonant frequencies and their dampings .

63. Frecka, T. R., and Viswanathan, T., Torque Controlled Drilling, SME Paper MR-75-177 (Society of Manufacturing Engineers, Dearborn, Mich., 1977).

A simple control system derives torque from measurement of horsepower and spindle speed. The system was developed by Cincinnati Milacron for NC machining centers and turret drills.

64. French, D., and Quinn, G., A Computer Program for Optimization of Cutting Conditions for Turning and Milling, Proc. 2nd N. Amer. Metalwork Res. Conf., Madison, Wisc., May 20-22, 1974 (Society of Manufacturing Engineers, Dearborn, Mich., 1974).

This paper describes a digital computer program to calculate the optimum cutting conditions for turning and milling operations.

65. Friedman, M. Y., and Tipnis, V. A., Cutting Rate-Tool Life Characteristic Functions for Material Removal Processes, Part 1: Theory, J. Eng. Ind., Trans. ASME 98, 481-486 (May 1976).

This concept enables a comprehensive development of a theory for economic optimization and encompassing commonly used criteria of cost, production rate, and profit rate in machining when more than one cutting variable is involved. The analysis of the theory is carried out for one and two independent cutting variables. See also V. A. Tipnis for Part 2 (reference 178). 
66. Frisch, J., and Mahr, P. F., On the Use of Analog Digital Conversion During DNC-Metal Cutting, Proc. N. Amer. Metalwork Res. Conf., Hamilton, Ont., Can., May 1973 (Society of Manufacturing Engineers, Dearborn, Mich., 1973).

Workpiece diameter, spindle misalignment and cutting forces were monitored during metal turning to compensate for tool wear and generate a cylinder of constant diameter within tolerances. A non-contacting displacement gage monitors the workpiece diameter and moves the cross feed to compensate for sensed errors.

67. Frost-Srith, E. H., and Marten, H. R., Optimization of the Machining Process and Overall System Concepts, Paper presented at one-day conference on Adaptive Control of Machine Tools, Macclesfield, England, April 1970.

A photomultiplier is used to convert an optical image of the wear land on the clearance face of the cutter to an electrical signal; and, by electronic timing and logic circuits, the size of the wear land can be inferred. The accuracy which can be achieved when cutting a medium carbon steel workpiece is very satisfactory and so far, there is no reason to doubt the commercial possibility of the system.

68. Frost-Smith, E. H., Optimization of the Machining Process and Overall Systems Concepts, Ann. CIRP 19, 385-394 (1971).

This paper shows that to get maximum benefit from optinizing the cutting process, it is necessary to study the overall workshop process. Two new methods of measuring wear characteristic are reported. The constriction-resistance method of measuring cutter wear in process is described briefly. Use of force measurements and tool-work thermocouple measurements is also discussed.

69. Gaevskii, Y. S., System for Optimizing Machine Tool Control Programs, Mach. Tool 44, No. 6, 10-12 (1973) [Stanki Instrum. (USSR), No.6, $6-7$ (1973)].

Describes a system for modifying a NC machine control program by automatic correction of the cutting process relationships. Correction is done by comparing information in the computer memory with data obtained when machining the first few components of a batch.

70. Gaudreau, M., An On-Line Technique for Tool Wear Measurement, M. S. Thesis, Massachusetts Institute of Technology (June 1975).

Describes instrumentation proposed for on-line experiments on a transfer machine. The variables and methods proposed for measurement are: electrical power - wattmeter; feed force - pressure sensors; tool temperature - fiber optic infrared sensors; workpiece temperature thermocouple; vibration - acceleroneter; torque - dynamometer.

71. Gautschi, G. H., Cutting Forces in Machining and Their Routine Measurement with Multi-Component Piezoelectric Force Transducers, Proc. 12th Int. Mach. Tool Des. Res. Conf., Manchester, Engl., September 15-17, 1971 (MacMillan and Co., Ltd., Lond., Engl., 1972).

Transducers and platforms for measuring forces with 1, 2, or 3 components and/or torques have been developed and are described. Practical aspects such as cross-talk between components, frequency 
response, and measuring and recording techniques are discussed and the possibilities of adaptive control by mounting transducers directly into machine tools are outlined.

72. Glew, C.A. W., Effectiveness of Vibration Analysis as a Maintenance Tool, Trans. Inst. Mar. Eng. 86, Part 2, 29-51 (1974).

The Canadian Forces use the portable octave-band analyzer as a machinery health monitor as part of their preventative maintenance program on ships and aircraft. Velocity measurements are taken near each principal bearing on a machine, on an overall and octave-band basis.

73. Glushko, V. V., and Shumov, V. D., Automatic Regulation of Cutting Rates in Double-slide Lathes, Mach. Tool. 44, No. 6, 13-15 (1973) [Stanki Instrum. (USSR), No. 6, 8-10 (1973)].

Describes systems for stabilizing cutting forces in a wheel-turning lathe having two tool slides. Cutting forces are gaged by measuring main drive motor current. Industrial tests show approximately $32 \%$ increase in productivity. 3 refs.

74. Goldenberg, A. C., Machine Program Analysis Using Transducers, (Proc. Ilth Int. ISA Instrum. Maintenance Manage. Symp., Rochester, N.Y., March 29-30, 1976), Book, Instrument Maintenance Management 11, pp. 5-10 (Instrument Society of America, Pittsburgh, Penn., 1976).

Accelerometers, velocity transducers, proximity sensors, LVDT, current or power sensing, flow, tension, load, thermocouples, encoders, and radiation sensors were integrated as part of the total system package.

75. Groover, M. P., Karpovich, R., and Levy, E. K., A Study of the Use of Remote Thermocouples to Estimate Tool Wear in Machining, Paper submitted to Trans. ASME (American Society of Mechanical Engineers, N.Y., N.Y., $1974)$.

76. Croover, M. P., and Levy, E. K., A Remote Sensor Method for Measuring Temperatures in Metal Cutting, Final Report to National Science Foundation under Grant GK 30418 (National Science Foundation, Wash., D.C., July 1974).

Uses a standard iron-constantan thermocouple located at the bottom face of the cutting tool insert. The scope of this work has been limited to single-point-insert type cemented carbide tools and continuous machining processes (turning). A number of important problem areas with the remote thermocouple technique remain to be solved before the device becomes commercially available.

77. Groover, M. P., Survey of Methods for On-Line Measurement of Tool Wear, SME Tech. Paper MR-75-146 (Society of Manufacturing Engineers, Dearborn, Mich., 1975).

This paper reviews the work which has been performed over about the last decade on the problem of on-line measurement of tool wear. For reasons of economics and control, it would be beneficial if the tool-wear status could be monitored while the operation was in progress. Nearly all the techniques surveyed in this paper rely on indirect measuring schemes. Among the variables used are cutting forces, temperature, sound or vibration, electrical resistance, and workpiece dimensions. 24 refs. 
78. Groover, M. P., Barman, A., and Levy, E. K., A General Equation for Estimating Tool Wear in Machining Using Remote Thermocouples, Proc. 3rd N. Amer. Metal Working Res. Conf., May 1975, Carnegie Press, Pittsburgh, Penn. (Distr. by Soc. Manu. Eng., Dearborn, Mich., 1975).

79. Groover, M. P., Monte Carlo Simulation of the Machining Economics Problem, J. Eng., Ind., Trans. ASME 97, 931-938 (August 1975).

A mathematical model of the machining operation is developed from experimental cutting data. The model considers two aspects of the machining process: tool wear and surface finish. The economic problem is first defined as a speed-only problem, and the effect of tool wear variability is investigated. The speed and feed problem is also studied with surface finish constraints imposed on the optimization procedure.

80. Grozmann, F. K., and Hemming, A. V., Problems Involved in the Development of Adaptive Techniques to Improve the Productivity of NC Lathes (Proc. 11 th Int. Mach. Tool Des. Res. Conf., Birmingham, Engl., September 1970), Book, Advances in Machine Tool Design and Research 1970 (Pergamon Press Inc., Elmsford, N.Y., 1971).

Special reference is made to the aspects of measurement of input variables. A NC lathe is modified to maintain constant tangential force measured as a ratio of spindle torque to workpiece diameter.

81. Hahn, R. S., Controlled-Force Grinding - A New Technique for Precision Internal Grinding, J. Eng. Ind., Trans. ASME 86, 287-293 (August 1964).

In controlled-force grinding, the grinding force or spindle deflection is prescribed, in contrast to the feed rate on conventional machines. One method of controlling the grinding force is to apply a prescribed force to an anti-friction cross slide. Another method is to monitor the grinding force with strain gages or other suitable dynamometer equipment and through a closed-loop system to provide continuously varying feed rates such that the spindle deflection or force is held constant.

82. Hariharan, R., and Narayanan, V., Adapative Control for Machine Tools, J. Indian Inst. Sci. 58, No. 5, 198-224 (May 1976).

Adaptive control (AC) of machine tools is a recent development in production engineering which aims at performing the cutting operation more efficiently. Usually feeds and/or speeds are adaptively controlled in accordance with the data obtained by sensing process parameters such as tool tip temperature, cutting force, spindle torque, vibration, etc. By virtue of its ability to economize the metal cutting process, AC can be expected to play a vital role in machine tool industry. AC systems applied to machining processes such as turning, milling, and grinding are discussed in this report. The principle, types, and advantages of AC systems are also described. 28 refs.

83. Hill, R. F., Measuring Tool Wear, based on ASME Paper $71-D E-42$ (Society of Mechanical Engineers, N.Y., N.Y., 1971).

Tool wear is determined from the radioactivity of the chips from a radioactive tool. The method is used to determine proper cutting conditions and the machinability of different cold-formed steel parts. 
84. Hitomi, K., and Nakanura, N., Optimization of Machining: Concept of Optimum-Seeking Machining and Experimental Results, Ann. CIRP 20, No. 1, 101-104 (1971).

Optimum-seeking machining (OSM) is a method in which the machining operation approaches an optimal state successively by revising the machining conditions with data obtained in practical work, the tool-life equation being unknown at the start of machining. In this paper, the fundamental concept of optimum-seeking machining and its algorithmic procedure are presented and an experimental result based on it is discussed.

85. Holland, C. L., In-Process Ultrasonic Measurement System for NC Mills, SME Tech. Paper 1Q-813 (Society of Manufacturing Engineers, Dearborn, Mich., 1976).

A new measuring technology for constantly monitoring aluminum plate thickness as it is being machined is described. The system uses a miniature ultrasonic transducer mounted inside a hollow milling cutter. Digital display of thickness measurements and printout of inspection records, including $x$ and $y$ locations of each ' $z$ ' measurement and a red print for out of tolerance reading are also features of the system.

86. Hoshi, T., Correlation Between Idling Vibration of Machine Tool and. Machining Chatter, Ann. CIRP 18, 289-295 (1970).

The mechanism of forced chatter induced by the idling vibration of a machine tool is presented, and instructions are derived to overcome practical problems.

87. Hoshi, T., Cutting Dynamics Associated with Vibration Normal to Cut Surface, Ann. CIRP 21, No. 1, 101-102 (1972).

In this method, the tool is attached to the end of a cantilevertype structure, and is excited sinusoidally by a small electrodynamic exciter. Experiments were performed on a lathe using a Plo carbide tool on $\mathrm{Pb} \cdot \mathrm{S}$ free machining steel, hardness $208 \mathrm{Hv}$, and chromium molybdenum steel (SCM 22), hardness $200 \mathrm{Hv}$. A load cell opposite the tool on the cantilever is shown.

88. Huber, J., and Centner, R. M., Test Results with Adaptively Controlled Milling Machine, Amer. Soc. Tool Manu. Eng. Paper MS68-638 (1968). The MB electronics type 124 seismic pick-up was used.

89. Idelson, J. M., Mueller, P. A., and Johnson, E. A., On-Line Trainable Adaptive Process Control, Technical Report AFML-TR-71-54, April 1971 (Manufacturing Technology Division, Air Force Materials Laboratory, Wright-Patterson Air Force Base, Ohio).

An investigation of on-line, trainable adaptive control using a surface grinder as the experimental evaluation test vehicle is described. Reductions in machining time of 6 to 68 percent were obtained for rough cuts (over non-adaptive control) and surface finish to better than $2 \mu i n$ $(0.05 \mu \mathrm{m})$ was obtained for finish cuts. On-line measurements included: vibration at the tool-work interface, spindle shaft torque, and speed.

90. Interactive Systems, Inc., Marketing Literature on the RTA-I Tool Wear Detection System (Interactive Systems, Inc., Ann Arbor, Mich.).

A system formerly marketed commercially by Interactive Systems makes use of small changes in the frequency signature of the tool 
vibration. A vibration transducer is mounted on each cutting head and the signal is fed into a mini-computer for analysis. The computer performs a power spectrum analysis on the vibration signal.

91. Jaeschke, J.R., Zimmerly, R. D., and Wu, S. M., Automatic Cutting Tool

Temperature Control, Int. J. Mach. Tool Des. Res. 7, 465-475 (1967).

The system maintains constant cutting temperature, as measured by a tool-work thermocouple, by varying speed. A new spring pick-up was used for signal transfer from the workpiece.

92. James, G., Adaptive Control at Work, Amer. Mach. 114, No. 2 (1970). The MB electronics type 124 seismic pick-up was used.

93. Kahng, C. H., and Viegelahn, G. L., The Effect of Thermoelectric Current on Tool Wear; Proc. 2nd N. Amer. Metalwork Res. Conf., Madison, Wisc., May 20-22, 1974, pp. 105-116 (Society of Manufacturing Engineers, Dearborn, Mich., 1974).

This paper presents the study of the characteristics of thermoelectric current and the results of an investigation on how these currents affect the life of the cutting tool.

94. Kahng, C. H., Lord, H. W., and Davis, T. L., The Effects of Chucking Methods on Roundness Error in the Boring Process, J. Eng. Ind., Trans. ASME 98, 233-238 (February 1976).

The effect of chucking force was measured at three force values [125, 156, and $187 \mathrm{lbf}(556,694$, and $832 \mathrm{~N})]$ using a three-jaw chuck and various wall thicknesses. A specially built strain-gage transducer was used to measure chucking force on the workpiece. The transducer is based upon work of Solaja and Kalajdzec, Ann. CIRP 16, 131-316 (1968).

95. Kaminskaya, V. V., et al., Trends in the Development of Adaptive Control, Mach. Tool 45, No. 8, 42-44 (1974) [Staki Instrum. (USSR), No. 8 (1974)]. At the present time there are no absolutely satisfactory transducer designs. Adaptive control seems simple, but it is difficult to implement because of problems connected with devising industrial measuring devices and the lack of knowledge of the phenomena occurring during cutting. 18 refs.

96. Kaneda, T., Kawauchi, M., Yamamoto, M., and Fukuzawa, S., Simple Method for Assessing the Machinability of Resulfurized Carbon Steels, J. I ron Steel Inst. Jap. 60(11), \$499 (1974) [HB Translation No. 9614]. Heasuring rate of drilling with an upright drill press under constant speed and load provides a fast and easy practical method of evaluating the machinability of resulphurized steels.

97. Kato, S., Yamaguchi, K., Watanabe, Y., and Hiraiwa, Y., Measurement of Temperature Distribution Within Tool Using Powders of Constant Melting Point, J. Eng. Ind., Trans. ASME 98, 607-613 (May 1976).

The method involves observation of the boundary line formed by melted and unmelted powder scattered on the tool. It is felt that temperature distribution within the tool may be easily and accurately measured in this manner. 
98. Kegg, R. L., Whittling Away Milling Inefficiencies, Automation, $82-84$ (September 1975).

Recent developments in technology of milling have been wasted by American Manufacturers. In spite of the achievements of numerical control, few firms actually use this manufacturing technique. Adaptive machining (such as torque-controlled drilling) is one way to respond to the problem of hole-making operations taking much of the time of a machining center.

99. Kellum, G. B., Signature Analysis of Plant Equipment, ASME Paper 71-Pet-14 (American Sociéty of Mechanical Engineers, N.Y., N.Y., 1971).

This paper is intended primarily to illustrate, through field experience, results which may be obtained through comprehensive signature analysis of critical plant equipment. Comprehensive signature analysis can be a powerful tool in reducing unexpected machinery failures. 11 refs.

100. Kistler, W. P., A New Approach to Tool Wear Monitoring Through Minicomputers and Modern Transducers, 1, A New Vibration Transducer for Tool Wear Monitoring (Proc. 27th Ann. Conf. Instrum. Soc. Amer., N.Y., N.Y., October 1972), Book, Advances in Instrumentation 27 (Instrument Society of America, Pittsburgh, Penn., 1972).

A new vibration transducer, specially designed for tool-wear monitoring through computers, will help achieve cost savings by offering a simple system, greater reliability, and longer life. The transducer employs a quartz-crystal sensing element and delivers a high-level, low-impedance signal which can be fed into a computer directly without requiring additional signal conditioning or amplification.

101. Kistler Instrumente AG, Piezoelectric Transducer, Patent No. UK 1266362, filed 17 July 1969.

A piezoelectric transducer for measuring stresses and forces set up in a machine tool workpiece support is described. It consists of a pair of force-transmitting members disposed to permit a number of piezoelectric plates to be positioned between them. The piezoelectric piates are interchangeable to provide a transducer system responsive to compression, shear, or torque forces depending on the orientation of the force-sensitive axes of the plates.

102. Kistler Instrumente AG, Automatic Machine Tool Control, Patent No. UK 1282459, filed 31 July 1969.

The control is effected by piezoelectric sensors which detect various forces, torques, and vibrations during the different.stages of operation and compare them to critical values, to emit a.control signal when a critical condition arises.

103. Kitagawa, T., Shirakashi, T., Usui, E., Experimental Measurement of Temperature Distribution in Tool/Chip Interface, Bull. Jap. Soc. Precision Eng. 9, No. 3, 83-84 (September 1975).

The temperature distribution is measured directly by a microthermocouple comprising a quartz-sheathed $0.02-\mathrm{mm}$ platinum wire insert in a small ( $~ 0.4 \times 0.4 \mathrm{~mm}$ ) U-groove electromachined into the tool-tip face. The tip is then ground to expose the end of the wire on the rake face, the chip completing the hot junction. The arrangement and some results obtained are illustrated and discussed. 
104. Kozochkin, M. P., Cutting Force Measurements in Machine Tool with Adaptive Controls, Mach. Tool 46, No. 11, 31-33 (1975) [Stanki Instrum. (USSR), No. 11 (1975)].

A method is described for measuring the three components of the cutting force using three transducers. Methodology is presented for estimating the calculation errors depending upon the errors in the initial data. 3 refs.

105. Kronenberg, M., Machining Science and Application, Theory and Practice for Operation and Development of Machining Processes (Pergamon Press, London, 1966).

Nearly fifty different types of dynamometers for measuring cutting forces have been developed using hydraulic, electrical, piezoelectric principles, and strain gages. Many references.

106. Kudnov, B. A., Semi-Automatic Device for Dynamic Analysis of Machine Tools, Mach. Tool 42, No. 2, 5-9 (1971) [Stanki Instrum. (USSR), 3-5 (1971)].

This paper gives a description and circuit for a semi-automatic device designed for dynamic research into machine tools. The amplitudephase frequency characteristics of the elastic system of the machine tool, required to determine its vibration resistance, can be determined by this device.

107. Kuljanic, E., An Investigation of Wear in Single-Tooth and Multi-Tooth Milling, Ann. CIRP 22, No. 1, 132-133 (1973).

In the present research it was shown that tool life is a nonlinear decreasing function of the number of teeth in the cutter. This function can be represented by a polynomial. The equation is valid in the range $Z=1$ to $Z=6$ cutter teeth.

108. Kuljanic, E., Effect of Stiffness on Tool Wear and New Tool Life Equation, J. Eng. Ind., Trans. ASME 97, 939-944 (August 1975).

An investigation indicated the effect of the stiffness of machining system depends on the number of teeth in the cutter, cutting speed, and feed. A new tool-life equation was developed to take this phenomenon into account. The tool life decreases with increasing number of teeth in the cutter. The static and dynamic stiffness was measured by means of a pulse-testing method which is both simple and reliable in determining the dynamic characteristics of a machining system. The cuts were interrupted periodically to measure the flank wear with the aid of a filter micrometer microscope.

109. Langhammer, K., The Cutting Forces as Characteristic Values for the Determination of Wear on Carbide Lathe Tools, VDI Z. (Germany) 115 , No. 8, 672-674 (June 1973).

For an adaptive control of the cutting process on lathing, the wear of the flank of the cutting tool is an important characteristic value. As there is no way of directly measuring the wear during the cutting process, one has got to search for indirect measuring techniques. A promising approach consists in the allocation of continuously measurable cutting forces to wear characteristics. 5 refs. In German. 
110. Langhammer, K., Cutting Forces as Parameters for Determining Wear on Carbide Lathe Tools and as Machinability Criterion for Steel, Carb. J. (May-June 1976).

Continuous measurement of cutting forces enables the tool wear to be ascertained at any time, conditional upon exact knowledge of the dependence of cutting force upon tool wear. Results on tests in this direction are given. From the correlations established abbreviated testing procedures might be developed, employing suitable cutting-force measurements to yield rapid information on the machinability of a steel melt. The three-component piezoelectric tool-holder dynamometer (made by Kistler Instrumente $A G$ ) is used.

111. Levi, R., and Rossetto, S., Some Considerations on Tool-Life Scatter and Its Implications, J. Eng. Ind., Trans. ASME 97, 945-950 (August 1975). The effect of tool-life scatter on the uncertainty of parameters of a typical tool-life model is analyzed using the joint confidence region approach. Some apparent contradictions concerning tool-life test data are explained in terms of their information content in the light of the concepts of probability likely to be held by various managers.

112. Levin, A. I., Automatic Control of Vibration in Machine Tools, Mach. Tool 44, No. 3, 45-49 (1973) [Stanki Instrum. (USSR) 44, No. 3, 30-33 $(1973)]$.

After discussing the circuits of automatic systems for the control of vibration when cutting, this article analyzes and compares the design properties of these circuits, showing that such systems make compensations to the variable component in the depth of cut. The conditions for the accurate stabilization of this value and for the substantial extension of the stability zone for the dynamic system of the machine are then developed, and optimum control algorithms are provided to reduce the forced vibrations of the tool relative to the machined workpiece. 10 refs.

113. Levy, E. K., Tsai, C. L., Groover, M. P., Analytical Investigation of the Effect of Tool Wear on the Temperature Variations in a Metal Cutting Tool, J. Eng. Ind., Trans. ASME 98, 251-257 (February 1976).

An analytical study of the effect of crater wear on the response of a remote thermocouple sensor is described. The remote thermocouple sensor is at present being developed as a device for the on-line measurement of tool wear.

114. Ling, C. C., Passive Damping Mechanism for Controlling Chatter in Turning Flexible Bars on a Lathe, Univ. Cincinnati, Ohio. (Available: Univ. Microfilms, Ann Arbor, Mich., Order No. 75-5314.)

The basic aim is to design an economic simple and effective mechanism to suppress chatter vibration when turning a long flexible shaft on a numerically controlled lathe. A forward-loop active damping compensation of structure dynamics in a closed-loop chatter mechanism has successfully suppressed chatter when turning such a shaft for the entire length of a workpiece in a single pass. Analytical and experimental studies have shown that the relative motion between cutting tool and workpiece has been effectively controlled and the resulting error in the workpiece size minimized by external damping. One of the simplest solutions is to introduce energy dissipation by means of coulomb damping. 
115. Lutz, J., A Process Measuring Wear on a Drilling Tool, U. S. Patent No. $3714822,1973$.

The wear on a drilling tool is measured by sensing vibrations produced during a drilling operation. It was found that these vibrations have a component indicative of the extent to which the tool is worn. This component may be partially isolated for determining tool wear.

116. Macotech Corporation, Functional Description of the MAC I Adaptive Control System for Milling Machines, 90-1001, (Macotech Corporation, Seattle, Wash.).

The system senses lateral cutter load or the force being exerted on the cutter throughout the machining process. The force-sensor systems, each consisting of four inductive transducers spaced $90 \mathrm{deg}$ apart around the spindle, are mounted on the spindle nose near the dust cover on each spindle. Special core material and winding techniques are employed in the transducers. They detect spindle displacement from $20 \mu \mathrm{m}(0.5 \mu \mathrm{m})$ up to the maximum spindle displacement. A horsepower-measuring sensor is used to monitor variations in motor load of each spindle. On a-c spindle motors a current transformer is used. A shunt is provided for $d-c$ motors.

117. Macotech Corporation, Specifications for the MAC VII Standard Adaptive Control System for Conventional and Tracer Profile Milling Machines (Macotech Corporation, Seattle, Wash.).

This system electronically senses lateral cutter load or force exerted on the cutter during the milling process and also includes a spindle-motor-load constraining system. The system is said not to be affected by normal operating temperature variations, vibration, spindle runout, bearing runout, and spindle residual magnetic fields.

118. MacManus, B. R., Machine Tools, U. S. Patent No. 3562477, filed 17 January 1973. Original Patent Appl. No. UK 5643/68.

A method of controlling and reducing the amplitude of vibration of a machine tool during machining of a workpiece comprises measuring the frequency of vibration of a machine tool during use of the machine tool, producing pulses of electrical current at the frequency of the vibration, and applying the pulses of current to the cutting zone, in a predetermined phase relationship to the tool vibration, so as to heat the cutting zone, thereby reducing or at least limiting the amplitude of vibration.

119. Mathias, R. A., Adaptive Controlled Profile Milling, SME Paper No. MS70563 (Society of Manufacturing Engineers, Dearborn, Mich., 1970).

In a feed-only adaptive-control (AC) system, spindle deflection is monitored by an LVDT. In the speed and feed AC system, spindle deflection and cutter torque are monitored. Strain gages are used for torque sensing.

120. Mathias, R. A., New Developments in Adaptive Control of Milling Machines (Proc. 13th Ann. Meet. Tech. Conf. Numerical Contr. Soc., Cincinnati, Ohio, March 28-31, 1976), Book, NC/CAM - The New Industrial Revolution, pp. 157166 (Numerical Control Society, Glenview, 111., 1976).

A software approach, the MAC microprocessor is described for the MAC/adaptive-control closed-loop system. 
121. Merchant, M. E., The Changing World of Manufacturing - A Challenge to DoD and Industry, Eighth Annual Tri-Service Manu. Tech. Adv. Group (MTAG) Meeting, Arlington, Tex., November 8-12, 1976 (Society of Manufacturing Engineers, Dearborn, Mich., 1976).

The world of manufacturing has been undergoing remarkable development and change and even more remarkable change lies ahead. The growing economic, productivity, and-social changes in manufacturing are producing a challenging need for development of advanced manufacturing technology of a type which has high potential to enhance manufacturing cost reduction and productivity and be capable of also delivering increased product performance.

122. Micheletti, G. F., Rossetto, S., and Ponti, M., Tool Vibration Pattern and Tool Life on Automatic Screw Machine (Proc. 11 th Int. Mach. Tool Des. Conf., Birmingham, Engl., September 1970), Book, Advances in Machine Tool Design and Research 1970, pp. 145-159 (Pergamon Press Inc., Elmsford, N.Y., 1971).

The outputs of a vibration transducer mounted on a screw machine were studied. No interrelation between vibratory power of the cutting tool and its life was observed.

123. Milewski, V., and Wolinski, H., At Valenite a Machine Monitor Becomes An Adaptive Control, Manu. Eng. Manage. 72, No. 4, 30-31 (April 1974).

The input electric power is converted to convenient horsepower readings via a machine monitor and recorder. The voltage, amperage, and phase angle are monitored and converted to horsepower. The system is preset to hold cutting action at a predetermined horsepower value.

124. Miller, R. C., and Sargar, A., Analysis of Machining Sounds and Its Potential Application to Adaptive Control, Cutting Tool Eng. (February 1973).

A signal from an accelerometer, mounted on the work or any part of the machine table, is processed using a spectral analyzer. It is shown that the spectrum is different for smooth machining and machining with chatter or edge build-up.

125. Moltrecht, R, H., Estimating Cutting Forces, SME Tech. Paper MR75-885 (Society of Manufacturing Engineers, Dearborn, Mich., 1975).

Machining cutting-force calculations are given for obtaining estimates of loads imposed by the cutter that must be resisted by drill jigs, machining fixtures, or tool holders. Accuracy of the calculations is dependent on that of the machinability data. Illustrations are included which show the directional forces involved in the calculations.

126. Moriwaki, T., Measurement of Cutting Dynamics by Time Series Analysis Technique, Ann. CIRP 22, No. 1, 117-118 (1973).

A cylindrical workpiece is turned by longitudinal feed of a small cutting tool mounted on a cantilever-type structure with flexibility only in the thrust force direction. The structure is randomly excited by an electrodynamic exciter. The wavy surface produced is removed by a rigid cutting tool. The cutting dynamics are examined in a frequency range of $0-500 \mathrm{~Hz}$. Main and thrust forces are measured by strain gages 
on the tool shank, and inner modulation is measured with a capacitive proximeter. The outputs are recorded on magnetic tape and fed into a computer.

127. Moriwaki, T., and Hoshi, T., System Identification on Digital Techniques, New Tools for Dynamic Analysis, Ann. CIRP 23, No. 2, 239-246 (1974).

Recent developments in theories, computation softwares and instrumentation for frequency analysis and systems identification involving digital computation are reviewed, and their applications to metal cutting process and machine tool dynamics are discussed. Applications to machine-tool dynamics, such as Fourier analysis of machine-tool vibrations, evaluations and measurements of the cutting process dynamics and transfer function measurements of machine-tool structures are described with examples. One example uses strain gages attached to the tool shank in the vicinity of the cutting edge.

128. Myers, S., and Hossain, S. Q. A. M. A., Logic Circuitry and Vidicon Measure Displayed Areas, Electron. Eng., 65-68 (February 1971).

This article describes the design and operation of a system which measures the actual wear area and mean wear with considerable ease and accuracy. The system, which is opto-electronic and employs digital techniques, is based on the principle that the magnitude of an area can be represented on an arbitrary scale, by the sum of the lengths of a large number of very fine lines subdividing the area. The area to be measured is magnified and then scanned by a vidicon, the output of which is fed to a monitor and digital logic circuitry.

129. Nakazawa, K., Improvement of Adaptive Control of Milling Machine by Non-Contact Cutting Force Detector, Proc. 16th Int. Mach. Tool Des. Res. Conf., Manchester, Engl., September 1975, pp. 107-116 (Halsted Press Division of John Wiley and Sons, Inc., N.Y., N.Y., 1976).

The principle of measuring torque is the magnetostriction effect. Four magnetic coil pairs are set around the measuring spindle (or tool holder). The exciting coil is set in the axial direction and crosses the torque-detecting coil at right angles. Where there is no force applied to a cutter, the torque detecting coil is magnetically symmetric with the magnetic flux caused by the exciting coil, and has no output. When a cutting torque is applied to the measuring spindle, stresses appear on the spindle surface at $45 \mathrm{deg}$ to the axial direction. The anisotropy of magnetic permeability of each principal direction of tension and compression makes the magnetic flux assymetric with respect to the torque detection coils and induces an output signal.

130. Nevins, J. L., Exploratory Research in Industrial Modular Assembly, Proc. Third NSF/RANN Grantees' Conference on Production Research and Industrial Automation, Cleveland, Ohio, October 28-29, 1975, pp. 65-72 (National Science Foundation, Wash., D.C., 1975).

The stability of force feedback-induced motions was analyzed and stability criteria developed using the Unimate 5000 under minicomputer control and a 6-axis force sensor. 
131. Nickols, 1., New Developments in Program Control Applied to Big Turret Lathes, Proc. 16th Int. Mach. Tool Des. Res. Conf., Manchester, Engl., September 1975, pp. 229-234 (Halsted Press Division of John Wiley and Sons, Inc., N.Y., N.Y., 1976).

This paper describes an automatic sequence control for programming all the movements of a big turret lathe. Special features are the electrohydraulic servo motors for transversing the slides, the method of avoiding long trailing flexible hoses, and the arrangements for obtaining accurate repeatability on a large number of different dimensions.

132. Nigm, M. M., Sadek, M. M., and Tobias, S. A., Prediction of Dynamic Cutting Coefficients from Steady State Cutting Data, Ann. CIRP 21 , No. 1, 97-98 (1972).

The method under discussion consists of two distinct stages. The first stage involves a dimensional analysis of steady-state cutting data leading to mathematical expressions which give the chip thickness ratio and force ratio. In the second stage, the steady-state cutting data are used to determine the incremental force components as a function of the cutting conditions.

133. Oguri, M., Fujii, H., Yamaguchi, K., and Kato, S., On Transient Cutting Mechanics at the Initial Stage of Peripheral Milling Process, Bull. Jap. Soc. Mech. Eng. 19(127), 61-70 (January 1976).

Experiments carried out are measurements of cutting force and its vector representation, observation of chip formation with microphotographs, and measurements of the stress distribution and chip contact length on the rake face and shear angle obtained from chip thickness. A transient period exists at the initial stage. The transient cutting mechanics change with tool advancement.

134. Ikushima, K., and Kakino, Y., An Analysis of Methods Used in Minimizing Thermal Deformations of Machine Tools, Proc. 16th Intl. Mach. Tool Des. Res. Conf., Manchester, Engl., September 1975, pp. 195-201 (Halsted Press Division of John Wiley and Sons, Inc., N.Y., N.Y., 1976).

The main objects of the paper are to clarify the effectiveness of the means employed for curbing thermal deformations due to inner heat sources and the optimum design concerning thermal deformation, if there is any. The analysis is conducted with a computer simulation using the finite-element method.

135. Olberts, D. R., A Study of the Effect of Tool Flank Wear on Tool-Chip Interface Temperatures, J. Eng. Ind., Trans. ASME 81, 152-158 (May 1959).

The tool-work thermocouple technique was used to measure the interface temperature. At all feeds and speeds a wear land of 0.01 in $(0.25 \mathrm{~mm})$ produced a lower interface temperature than a sharp tool or ones with wear land beyond 0.01 to 0.031 in $(0.25$ to $0.79 \mathrm{~mm})$. Discussion on thermocouple calibration is presented.

136. Opitz, H., Effect and Control of Chatter Vibrations in Machine Tool Processes, Scientific Report No. 5, I September-30 Nov 1967, Contract AF $61(052)-966$. 
After examining the systematic errors of frequency response measurements caused by the peaks in the power and cross-power spectra, the statistical errors due to external noise signals will be analyzed in this report. Furthermore, a general mathematical procedure is derived; by means of this it is possible to compute the subfrequency responses of a multiple-input linear system. Cutting force measurements in wave-on-wave cutting operations with the further improved test set-up show a strong dependence of the frequency response magnitude on the phase angle between the two contours of the chip.

137. Opitz, H., and Bernardi, F., Investigation and Calibration of the Chatter Behavior of Lathes and Milling Machines, Ann. CIRP 18, 335-343 (1970). A simple procedure is described for the calculation of theoretical stability charts of lathes and milling machines. Based upon the theory of regenerative chatter, the system machine-tool-cutting process is reduced to a non-intermeshed closed control loop, of which the stability behavior is representative for the chatter-free cutting performance.

138. Opitz, H., and Werntze, G., Application of a Process Control Computer for Measurement of Dynamic Cutting Coefficients, Ann. CIRP 21, No. 1, 99-100 (1972).

The dynamic cutting forces are measured by a dynamometer and stored on a magnetic tape together with the measured dynamic displacements. Simultaneously, the signals of a digital encoder or of a revolution mark which is fixed to the end of the spindle are stored on the magnetic tape. The analysis of the measured signals is carried out by a process control computer (siemens 305).

139. Oxford, C., Jr., Shape-Up with Sharper Drills, Mach. Tool Blue Book 70 , No. 9, 61-62 (September 1975).

Wear is classed as two types - abrasive wear of the relief surface, progressing in three stages, and formation of a crater on the rake face some distance behind the cutting edge. The first stage of abrasion occurs as break-in-wear. Next there occurs a fairly uniform increase in wear-land length, and finally higher forces between the land and work surface cause high temperature and accelerated wear. Resharpening before this stage gives optimum hole-drilling capability for drills; if postponed, drill damage causes reduction in the number of resharpenings possible.

140. Oxford, C., Jr., Selecting a Feed and Speed? Remember...FEED is the Key, Mach. Tool Blue Book 71, No. 10, 85-90 (October 1976).

In general, better tool life at a given production rate can be obtained by increasing feeds and reducing speeds. The effect of these changes on other aspects of machining, such as power requirements, cutting edge strength, workpiece strength, and material, chip disposal, chip breaking, and surface finish, is discussed.

141. Parks, J. R., Sensory Aids for Machine Tools, Conf. Ind. Robot Technol. (CIRT), Nottingham University, March 27-29, 1973 (National Physical Laboratory, Teddington, Engl., 1973).

There is a need for a new approach in instrumentation. It is suggested that two approaches are relevant - 1) improved monitoring 
of tools to reduce losses, and 2) piece-part inspection to achieve 100\% inspection and to improve acceptable quality levels. Areas of investigation were (a) automatic inspection, (b) automatic assembly, (c) order picking, and (d) container stuffing.

142. Pearce, D. F., and MacManus, B. R., Dynamic Chip Formation and Its Significance to Machining Stability, Proc. Inst. Mech. Eng. 187, No. 21 , 273-283 (1973).

The physical processes of dynamic chip formation were examined experimentally using direct photographic techniques; motion in the cutting zone was frozen by synchronizing an intense stroboscopic flash to particular positions in the waveform of the cutting force. Measurements obtained under conditions of controlled vibratory machining gave instantaneous values of the uncut chip thickness, tool-chip contact length, effective shear angle, and cutting force. Amplitude and phase measurements of the tangential component of the cutting force on wave removal were directly related to the deduced waveform of specific contact length, a process yielding considerable predictability.

143. Peiter, A., Kieferu, G., and Schwarz, S., Comparable Control of a $20 \mathrm{kN}$ Universal Cutting Machine with Electronic Force Measuring Indicator and Data Transmission, Ind.-Anz. 97, No. 45, 915-918 (June 1975).

Paper describes an automatic procedure for comparison of accuracies of NC cutting machines of the same type. Data recording forms are illustrated. I ref. In German.

144. Peklenik, J., Selijak, Z., Leskovar, P., and Justin, B., Contribution to the On-Line Identification of the Cutting Process, Ann. CIRP 22, No. 1, 43-44 (1973).

In these investigations a piezoelectric three-component dynamometer with a natural frequency of $3 \mathrm{kHz}$ was employed. The power spectra may also be computed by a special plug-in unit of an oscilloscope. Graphs are given indicating the changes in power as a function of increasing wear land for cutting speeds of 200 and $160 \mathrm{~m} / \mathrm{min}$.

145. Peters, J., Venherck, P., and Van Brussel, H., Measurement of the Dynamic Cutting Coefficient, Ann. CIRP 20, No. 2, 129-136 (1971).

The three sections of the paper deal with the validity of machinetool acceptance tests and possible programming of the chatter constraint in the programming NC machine tools. Also given are the current methods used by members of the Machine Tool Group of CIRP for measuring dynamic cutting stiffness. A new method is developed using the test rig instead of a dynamometer, which overcomes the main difficulties mentioned and permits the prediction of the stability chart within a few percent. The assumptions made in the shear-plane model are weighted out against the experimental results. 23 refs.

146. Pfeifer, H., Practical Measuring Instruments, Antriebstechnik 9, No. 5, 157-162 (May 1970).

The article deals with some measuring instruments for the measurement of continuously variable feed speeds and of machine vibrations in the machine tools industry, especially suitable for workshops. Indications for the use of these instruments and various diagrams are given. In German. 
147. Polacek, M., Vanek, J., and Nemec, I., Measuring Methods in Research on the Dynamic Characteristics of Machine Tools, Based on the Principle of Double Modulation, Int. J. Mach. Tool Des. Res. I1, No. 4, 273-282 (December 1971).

Electromechanical transducers of a modulation type are suitable for obtaining the product of two time variables based on the "double modulation" method. The paper describes applications of the method for obtaining of real part of the frequency characteristic of the mechanical structure and for measurements of the spindle rotation accuracy.

148. Rakht, A. K., Sankar, T. S., and Osman, M. O. M., On the Relationship Between the Random Metal Cutting Forces and the Surface Formation in Finish-Turning, SME Technical Report MSR75-01 (Society of Manufacturing Engineers, Dearborn, Mich., 1975).

An investigation was carried out to establish a relationship between the characteristics of cutting-force fluctuations that cause vibratory response of the machine-tool-workpiece system and the formation of surface texture in a turning operation. The cutting forces were measured using a specially built three-component dynamometer. 14 refs.

149. Ramalingam, S., and Watson, J. D., Tool-Life Distributions, Part 1: Single-Injury Tool-Life Model, ASME Paper 76-WA/PROD-36 (American Society for Mechanical Engineers, N.Y., N.Y., 1976).

This paper presents the results obtained on the assumption that the useful life of a tool is terminated by a single catastrophic injury. Cases where resistance to tool failure is time independent and time dependent are examined.

150. Ramalingam, S., Tool-Life Distributions, Part 2: Multiple-Injury Tool-Life Model, ASME Paper 76-WA-PROD-37 (American Society of Mechanical Engineers, N.Y., N.Y., 1976).

The expected tool-life distribution in the case of tool failure from multiple injuries due to constant time-independent stochastic hazards is shown to be a gamma distribution. The result obtained is based on a linear wear assumption. The model is further extended to ensure applicability in the nonlinear wear region.

151. Roethelt, F., and Peklenik, J., Assessment of the Force Controlled Internal Grinding Process Using Random Process Techniques, Ann. CIRP 22, No. I, 97-98 (1973).

A hydraulic control system was developed for controlling the constant thrust force on an internal grinding machine, as well as force, and dimensional measuring systems for the on-line work. The system is described in F. Roethel, Adaptivno Krmiljenje Sistenaza Bitrabhe Brusenje in On-Line Identifikacija Brusilnega Procesa Z Ozirom na Geometricne Slucajnostne Jhdne in Izhodne Funkcise. Ph.D. Thesis, 1972, University of Ljubljana.

152. Rubenstein, C., An Analysis of Tool Life Based on Flank-Face Wear, 1 Theory, J. Eng. Ind., Trans. ASME 98, No. 1, 221-226 (February 1976); 11 - Comparison of Theory with Experimental Observations, J. Eng. Ind., Trans. ASME 98, No. 1, 227-232 (February 1976).

Continuous flank-face wear is considered, and an analysis is given in which wear is attributed to adhesion between tool and workpiece materials 
while acknowledging that other mechanisms could produce continuous flankface wear. The fundamental basis on which the analysis rests is the realization that in a continuous cutting operation the temperature of the subsurface layer of the workpiece increases much less than that of the subsurface layer of the tool.

153. Saravanja-Fabris, N., and. D'Souza, A. F., Nonlinear Stability Analysis of Chatter in Metal Cutting, J. Eng. Ind., Trans. ASME 96, 670-675 (May 1974).

A relationship is developed between the chip thickness and forces in cutting under dynamic conditions based on existing experimental results and exhibiting active hysteresis. The oscillations in chip thickness lead the oscillations in cutting forces for all frequencies. A nonlinear theory is developed based on the describing function approach.

154. Sarnicola, J.F., and Boothroyd, G., Machine Tool Chatter: Effect of Surface Slope on Machining Forces During Wave Removing, J. Eng. Ind., Trans. ASME 96, 1202-1206 (November 1974).

orthogonal cutting tests were performed on a milling machine modified to carry out a planing operation at a low constant cutting speed. A "sharp" HSS tool with a 10 deg clearance angle was used with care being taken to regrind and hone the tool after each cut. A two-component milling dynamometer, dead weight calibrated, was used to measure tool forces in the thrust and cutting directions. The workpiece specimens were strips of $90 / 10$ brass 4 in $(100 \cdot \mathrm{mm})$ long and 0.135 in $(3.43 \mathrm{~mm})$ thick.

155. Sarwar, M., and Burdekin, M., Chatter During Turning, Mach. Prod. Eng. 128, Part I N3294, 79-82 (January 1976); Part 2 N3296, 131-133 (February $\overline{1976) . ~}$

The data, presented in graphical form, should prove useful to the production engineer who is confronted with the problem of chatter, when means for avoiding this effect are restricted to changes in cutting conditions and workpiece material.

156. Sata, T., Inamura, T., and Matsushima, K., Analysis of Three Dimensional Cutting Dynamics, Ann. CIRP 22, No.1, 119-120 (1973).

A new analytical method is presented for evaluating the dynamic cutting coefficients in generalized three-dimensional cutting. The analytical results show good agreement with experiments carried out on a turning operation with various cutting-edge angles and feed rates. The tool is excited by an electro-hydraulic servo mechanism. Forces in cutting, feed, and thrust directions are measured with a 3 -component tool dynamometer. Displacement is measured with a proximity type meter. The signals are sent to a transfer function analyzer to obtain stiffness transfer functions.

157. Selvam, M. S., Tool Vibration and Its Influence on Surface Roughness in Turning, Wear 35, No. 1, 149-157 (November 1975).

The frequency content of tool vibration and the surface profile in turning under normal cutting conditions was studied by measuring the frequency spectra of tool vibration and the surface profile. The 
predominant frequencies of tool vibration and the surface profile in the circumferential direction were found to be the same. The cutting speed, workpiece rigidity, and the method of fixing the workpiece were found to influence the surface roughness and tool vibration.

158. Shillam, N. F., The On-Line Control of Cutting Conditions Using Direct Feedback, Proc. 12th Int. Mach. Tool Des. Res. Conf., Manchester, Engl., Proc. 12th Int. Mach. Tool Des. Res. Conf., Manchester, Engl., September 15-17, 1971 (MacMillan and Co., Ltd., London, Engl., 1972).

The systems described were fitted to a center lathe and a vertical mill. Thrust force was controlled on the lathe. On the mill, table vibration was sensed and feed rate varied. Both machines controlled the tool temperature by monitoring the electromotive force developed between tool and workpiece and varying cutting speed accordingly.

159. Shiozaki, S., and Miyashita, M., Dynamics and Design of Dynamometer, Ann. CIRP 18, 663-675 (1970).

In the case of measuring a grinding force, the dynamic behavior of the dynamometer, its influence upon the grinding system, and then the fidelity of measurement as a whole system are considered. An octohedral elastic-ring dynamometer, allowable error $20 \%$ and frequency ranges $0-1700$ $\mathrm{Hz}$ (normal direction) and $0-1000 \mathrm{~Hz}$ (horizontal direction), and a twoforce component piezoelectric dynamometer with natural frequency (normal direction) as high as $180 \mathrm{kHz}$ and static rigidity more than $100 \mathrm{kgf} / \mathrm{um}$ have been experimentally produced and expected results have been obtained.

160. Solaja, V., Selected Results from a Project on Drilling, Ann. CIRP 21, No. 1, 33-34 (1972).

Within the framework of a long-term project on machinability carried out for the Yugoslav metalworking industries, considerable attention was paid to the drilling of metal, with the specific features of tool wear as the basic criterion in evaluating cutting performance of twist drills. The purpose of this paper is to report a few selected topics from the research program which have not been presented to engineering circles outside Yugoslavia.

161. Solaja, V., and Jukelja, D., Identification of Tool Wear Rate by Temperature Variation, Ann. CIRP 22, No. 1, 5-6 (1973).

Research in the thermodynamics of cutting suggests a correlation between tool wear and tool temperature. Tool temperature is measured with a remote copper-constantan thermocouple.

162. Solaja, V., and Kalajdzic, M. J., Interface Machine-Tool/Cutting Process in the Optimization of Manufacturing Systems, Ann. CIRP 22, No. 1 , $121-122(1973)$.

It has been shown that external disturbance introduced into a radial drilling machine system in an axial direction as a harmonic force bears an influence on tool wear. Tool wear seems to be directly associated with satisfactory movement of chips, and a strong positive effect of the exciting frequency near the natural frequency of the system was established. 
163. Sperry Gyroscope Co., Ltd., Measurement and In-Process Control of Small Bores, Contract AF 33(657)-11267 FLD/GP 13/8, March 1967, Project MMP7-907 (Sperry Gyroscope Co., Ltd., Montreal, Quebec).

This paper includes a description of laser interferometer measurement and of a piezoelectric actuacor used to change the radius of the cutting tool to compensate for errors detected with the interferometer. Strain gages measure the strain on the tool due to the cutting forces. Data on flank wear vs. cutting speed and effect of cutting fluids are also given.

164. Spescha, G. A., Piezoelectric Multi-Component Force and Moment Measurement, Kistler reprint 20.065 e (Translation of reprint 20.065 d), Kistler Instrumente AG, Switz., 11 pages.

Basic principles of the quartz piezoelectric multicomponent force transducers (developed at Kistler) are discussed. The transducers and their applications are described briefly, including measurement of cutting forces in machine tool operations. Bibliography with 29 refs.

165. Spur, G., and Leonards, F., Kontinuierlich Arbeitende Verschleiss Sensoren Fur ACO-Systeme Bei Der Drehbearbeitung, Z. Wirschaft, Fertigung 68, No. 10, 517-519 (1973).

A resistance network with resistors of varying lengths was sandwiched between two thin layers of insulation and attached to the flank surface of the cutting tool. As wear proceeds on the tool flank, the longer resistors are affected one by one, and the resulting electrical signal provides a quantized indication of the wear level. A considerable amount of additional fabrication must be done on each cutting tool in order to use this sensing scheme.

166. Stankiewicz, N., Maintenance - Make or Break Factor in Drilling Machine Performance, Automation, 86-87 (September 1975).

The Kingsbury Performance Monitor Controller (PMC) incorporates a Hewlett-Packard model 2100 16-bit minicomputer to monitor an automatic machine. Normal machine operation is immediately terminated if a malfunction is detected. The PMC interrogates the machine tool, identifies the faulty component, and reports the location.

167. Subramanian, K., Sensing Drill Wear and Prediction of Drill Life, S. M. and M. E. Thesis (Massachusetts Institute of Technology, June 1974).

Torque, thrust, and power input were measured in a drilling operation and were found to increase with tool wear. The magnitude of these variables increases considerably, but the major change is accompanied by total failure of the cutting edge.

168. Subramanian, K., and Cook, N. H., Sensing of Drill Wear and Prediction of Drill Life, ASME Paper 76-WA/PROD-33 (American Society of Mechanical Engineers, N.Y., N.Y., 1976).

Torque, thrust, and power are observed to be functions of drill wear.

169. Szakovits, R. J., and D'Souza, A. F., Metal Cutting Dynamics with Reference to Primary Chatter, J. Eng. Ind., Trans. ASME 98, 258-264 (February 1976). 
The experimental set-up on a lathe sinusoidally oscillates the tool, parallel to the feed, and records the motion and the fluctuating cuttingand thrust-force components resulting from the tool oscillation. The set-up uses a tool dynamometer consisting of a double cantilever carrying tension and compression strain gages.

170. Takeyama, H., Doi, Y., Mitsuoka, T., and Sekiguchi, H., Sensors of Tool Life for Optimization of Machining (Proc. 8th Int. Mach. Tool Des. Res. Conf., Manchester, Engl.: September 1967), Book, Advances in Machine Tool Design and Research 1967, pp. 191-208 (Pergamon Press Inc., Elmsford, N.Y., 1968).

Rate of change of cutting force is correlated with tool wear.

171. Takeyama, H., Sekiguchi, H., and Takada, K., One Approach for Optimizing Control in Metal Cutting, Ann. CIRP 18, 345-351 (1970).

A performance index suited to the on-line control of a machine tool has been established through extensive experiments. Optimization can be achieved by measuring the derivative of cutting force, which is proportional to the tool wear rate, and by computing the performance index taking important constraints into consideration.

172. Takeyama, H., and Sakata, 0., Optimization of Dynamic Performance in Tool Holder, and Work System, Ann. CIRP 20, No. 1, 77-78 (1971).

The simplified linear model of tool holder-tool workpiece system has been theoretically analyzed and simulated. It has been demonstrated that by varying properly the transfer parameters of the tool holder, the dynamic performance of the whole system can be controlled and improved to prevent self-excited vibration.

173. Takeyama, H., Sekiguchi, H., and Takada, K., Direct Measurements in Metal Cutting Operations, Werkstatt Betr. 106, No. 9, 709-714 (September 1973).

The significance of direct measurements during metalworking operations for the development of adaptively controlled machine tools, i.e., measurements of cutting power, tool wear, workpiece dimensions, and chatter vibrations, is emphasized. Some systems developed for this purpose by a Japanese laboratory for machine design are described. 8 refs. In German.

174. Tanaka, Y., and Ikawa, N., Accelerometer Applications to Tool Dynamometer with Improved Dynamic Response, Ann. CIRP 18, No. 4, 353-359 (May 1970).

The dynamometer, designed by combining an accelerometer with a conventional strain instrument, makes it possible to measure dynamic forces with frequencies of up to $40 \mathrm{kHz}$ as well as the static case. It is also shown that the dynamometers measure successfully the rapidly changing forces in interrupted cutting and in so-called single-cut grinding.

175. Taylor, F. W., On the Art of Cutting Metals, ASME Annual Meeting, New York, December 1906 (The American Society of Mechanical Engineers, N.Y., N.Y., 1907).

A rope brake was used on one step of the cone pulley of the lathe. The brake consisted of a double rope slung around the pulley, having each of its ends attached to spring balances, one of which is stationary and 
the other attached to the end of a draw screw. The lathe motor current while cutting is duplicated with the brake applied. The differences in the readings of the balances gives an indication of the load from which tool pressure can be calculated. Total pressure of the chip on the tool in cutting cast iron varies from 35 to 99 tons per square inch sectional area of chip ( 480 to $1400 \mathrm{MPa}$ ) depending on hardness and feed rate.

176. Tipnis, V. A., Finding Your Best Machining Conditions, I - Identify the Problem, Mod. Mach. Shop 48, No. 6, 82-91 (November 1975).

The machining principles of chip formation, build-up edge formation, tool wear, tool life, cutting forces, horsepower requirements, and temperatures in the cutting zone are reviewed. Data are given on tool life and power requirements for various alloys. Useful shop formulae for removal rate, horsepower, and torque are given for turning, milling, drilling, and broaching.

177. Tipnis, V. A., Development of Mathematical Models for Adaptive Control Systems (Proc. 13th Ann. Meet. Tech. Conf. Numerical Contr. Soc., Cincinnati, Ohio, March 28-31, 1976), Book, NC/CAM - The New Industrial Revolution, pp. 149-156 (Numerical Control Society, Glenview, 111., 1976).

A Cincinnati Cinova 80 milling machine was modified and instrumented for machining data over a wide range of conditions. A spindle force sensor unit (MAC-I, Macotech Co.), mounted on the spindle measures forces parallel to and perpendicular to the table feed. Spindle rpm was monitored through a digital rpm counter. Spindle horsepower was measured with a digital wattmeter.

178. Tipnis, V. A., and Friedman, M. Y., Cutting Rate-Tool Life Characteristic Functions for Material Removal Process, Part 2: Verification and Applications, J. Eng. Ind., Trans. ASME 98, 487-496 (May 1976).

Two statistically designed experiments, one on sawing and the other on milling, verifying the proposed concept are described. The applications discussed include economic selection of machining conditions, economic tool life determinations, comparison of machining response, objective function for adaptive control, and maximization of material removal at a desired level of surface integrity. For Part 1 , see reference 65 .

179. Tipton, H., Machine Performance Rises to New Levels as Control Costs Fal1, Metalwork Prod. 120, No. 10, 131, 140 (October 1976).

Developments are leading to a whole new approach to machine tool design and construction, and are radically changing manufacturing philosophy. This article describes the different types of control that are available. Four main groups are highlighted: manual, sequence, numerical, and adaptive control.

180. Tlusty, J., and Goel, B. S., Measurement of the Dynamic Cutting Force Coefficient, Proc. 2nd N. Amer. Metalwork Res. Conf., Madison, Wisc., May 20-22, 1974, pp. 649-665 (Society of Manufacturing Engineers, Dearborn, Mich., 1974).

The problem of the dynamic cutting force coefficient as part of the problem of self-excited chatter in machining is formulated in general, 
and its significance explained for the choice of optimum cutting conditions with respect to the workpiece material susceptibility to chatter. The equipment built at McMaster and the techniques of processing the signals using a Fourier analyzer are described. Vibration is measured with strain gages or a capacitive probe. Forces are measured with piezoelectric load cells. 28 refs.

181. Tlusty, J., and Elbestawi, M. A. A., Analysis of Transients in an Adaptive Control Servomechanism for Milling with Constant Force, ASME Paper 76-WA/ PROD-31 (American Society of Mechanical Engineers, N.Y., N.Y., 1976).

Characteristics of a reasonably well-adjusted NC servo are given both as measured and as modeled. Nominal forces of $4100 \mathrm{~N}$ in Case 1 , peak forces of $6550 \mathrm{~N}$ in Case 2, and an initial maximum of 15,190 $\mathrm{N}$ with peak values of about $5000 \mathrm{~N}$ after $0.25 \mathrm{~s}$ in Case 3 are given. The equipment is described in another publication: Tlusty, J., Koren, Y., and MacNeil, P., Numerical and Adaptive Control for Die Sinking, Proc. Int. Conf. Prod. Engng. Res., Tokyo, Japan (Japan Soc. Prec. Engng., 1974).

182. Tlusty, J., Yellowley, I., and Konrad, G., Tool Wear in the Peripheral Milling of a Low Carbon Steel, ASME Paper 76-WA/PROD-35 (American Society of Mechanical Engineers, N.Y., N.Y., 1976).

It is the purpose of this paper to examine the results of a series of milling tests carried out at practical cutting conditions, and to attempt to explain the results in the light of the present state of knowledge of the process. Some indications of the nature of the process at much higher metal removal rates are also discussed. The cutting forces were measured parallel and perpendicular to the feed direction using a piezoelectric dynamometer.

183. Tobias, S. A., and Koenigsberger, F., Eds., Proc. 13th Int. Mach. Tool Des. Res. Conf., Birmingham, Engl., September 18-22, 1972 (MacMillan Press Ltd., Lond., Eng., 1973).

Seventy-nine papers were presented at the conference covering recent developments in automation, including NC control and DNC control and on plastic-forming processes, in particular high energy rate forming, which includes powder forming and sinter forging. Other sessions covered machine tool vibration, with special reference to chatter and to metal cutting and tool wear, with a complete session on grinding.

184. Tolotta, S., Development and Application of Radio Telemetry for the Solution of Naval Machinery Problems, Proc. Int. Symp. on Mar. Eng., Tokyo, Jap., November 12-15, 1973, pp. 15-26 (Marine Engineering Society, Tokyo, Jap., 1973).

With the advent of solid-state electronics, it became possible to build sophisticated radio telemetry systems which could operate in severe environmental conditions such as high centrifugal force and high temperature. This led to the development and application of telemetry for use in resolving many rotating machinery problems.

185. Tseitlin, L. N., and Shimokhin, A. K., Magnetoelastic Torque Transducers for Adaptive Machine Tools, Mach. Tool 45, No. 8, 56-59 (1974) [Stanki Instru. (USSR), No. 8, 35-37 (1974)]. 
This paper deals with magnetoelastic torque transducers used to measure cutting force parameters in lathes and milling machines with adaptive control. Spindle assembly and turret head designs incorporating transducers are described. 2 refs.

186. Tustin, W., Measuring Shock and Vibration, 2, Instruments for Reading Vibration, Plant Eng. 26, No. 8, 94-96 (April 1972).

Protection against vibration damage must begin with accurate determination of the amount of vibration present. Instruments for measuring vibration can vary from relatively inexpensive indicating types with limited capability, to sophisticated recording types that provide highly accurate information that can be used in detailed analysis of the problem.

187. Uehara, K., New Attempts for Short Time Tool-Life Testing, Ann. CIRP 22, No. 1, 23-24 (1973).

A fine conductive strip made from graphite or thin metal film was printed on the clearance surface which was insulated by a thin layer of heat-resisting paint. The length of this resistor decreases with the progress of flank wear and this decrease is measured continuously by the change of electrical resistance.

188. Venkatesan, S. R., and Chandrasekaran, H., Tool-Work Contact Stresses in Metal Cutting, Proc. 3rd All-India Mach. Tool Des. Res. Conf., Bombay, India, December 1969, pp. 184-188 (India Institute of Technology, Madras, India, 1969).

Complete details of experimentation and the method of stress separation are given for the study described in reference 39 , by $H$. Chandrasekaran and R. Nagarajan. The method uses a photoelastic tool to machine a soft metal.

189. Welch, J. D., Automatic Feedrate Regulation in Numerically Controlled Contour Milling, MIT Electronics Systems Laboratory Report No. 8436-R-1 (Massachusetts Institute of Technology, June 1960).

A method of using a feedback signal from the cutting process to determine feedrate is presented. Feedback signal is the electromotive force between tool and work. However, there is a nonlinear relationship between the feedrate and thermoelectric signal. Advantages and disadvantages of imbedded thermocouples and infrared indicators are discussed.

190. Weller, E. J., Schrier, H. M., and Weichbrodt, B., What Sound Can Be Expected from a Worn Tool?, J. Eng. Ind., Trans. ASME 91, 525-534 (August 1969).

Data from experiments on a lathe using five grades of cemented carbide inserts and AISI 1045 steel indicate that as wear land increased the magnitude of 4-8 kHz vibrations increased. Tool vibrations were divided into two frequency components, $0-5 \mathrm{kHz}$ and $4-8 \mathrm{kHz}$. An alarm is activated when the ratio of these signals exceeds a predetermined value.

191. Whetham, W. J., Milling Machine Control System and Milling Force Sensor Therefor, U. S. Patent No. 3602090, filed February 27, 1970. 
The sensor includes a plurality of magnetic transducers which are disposed about the periphery of a portion of the machine spindle. The transducer primaries are provided with an a-c exciting voltage, and the secondaries are connected in opposition so that the common output signal therefrom has a zero $d-c$ content under conditions of zero spindle loading. When a sideload or end load is supplied to the cutting tool, and thus to the spindle, during the milling process, the common output signal principally comprises an a-c component which is amplitude modulated in proportion to the degree of spindle deflection. A demodulator converts the amplitude modulated component into a $d-c$ signal representative of milling force. This signal is then supplied to a controller in the feedrate system.

192. Whetham, W. J., Low Cost Adaptive Control Unit Manufacturing Methods, Tech. Report No. AFML-TR-73-263 (Air Force Materials Laboratory, Wright-Patterson Air Force Base, Ohio, November 1973).

The objective was to evaluate the low-cost retrofitable adaptive control (LCRAC) system to determine quantitatively the advantages of adaptive control over conventional NC machining. The LCRAC force sensors are calibrated to provide a voltage proportional to the actual machining forces.

193. Wilkenson, A. J., Constriction-Resistance Concept Applied to Wear Measurement of Metal Cutting Tools, Proc. IEE (Lond.) 118, No. 2, 381-386 (February 1971). The paper describes a mathematical model for the tool-work-pieceinterface resistance in a single-point oblique-cutting operation on a lathe. The model is developed using the concept of constriction resistance, and is verified by practical measurements.

194. Williams, R. A., A Study of the Drilling Process, J. Eng. Ind., Trans. ASME 96, 1207-1215 (November 1974).

Equations are derived for the prediction of total torque and thrust, given the cutting conditions, drill geometry, and an empirical factor which is related to the work material. Continuous torque and thrust levels were monitored using a strain gage dynamometer coupled through an amplifying system to a two-pen recorder.

195. Wood, N. F., Low-Cost System Revives Adaptive Control, Mach. Tool Blue Book, No. 2, 68 (1973). MAC-1 (Macotech Co.) cutting force stabilizing unit.

196. Yamazaki, K., Yamada, A., and Swami, S., A Study on Adaptive Control in an NC Milling Machine, 24 th Gen. Assembly Int. Inst. Prod. Eng. Res. (CIRP), Kyoto, Jap., 1974 (Verlag Technische Rundschau Hallwag, Bern, Switz., 1974). Methods of in-process measurement of tool wear are proposed. Experimental equations describing the tool wear and cutting forces were obtained. An analysis of the frequency domain of cutting vibrations indicated that the frequency of the peak amplitude in the vicinity of the resonant frequency of the cutter system decreased with increase in flank wear, regardless of cutting conditions. Also, the amount of light reflected from the wear land correlates well with flank wear. 
197. Young, F. W., An Investigation of Available Signals for Adaptive Control of Machine Tools, S. M. Thesis (Massachusetts Institute of Technology, May 1970).

Vibrations from a turning operation were investigated. Spectral density functions for the frequency ranges of $25 \mathrm{~Hz}$ to $7 \mathrm{kHz}$ and $20 \mathrm{~Hz}$ to $40 \mathrm{kHz}$ were computed from experimental data of tungsten carbide and $\mathrm{M} 2$ high speed tools as a function of tool wear. No useful results were found.

198. Ziegler, L., Penny-Wise, Pound-Foolish Thinking Wastes NC Benefits, Automation, 84-85 (September 1975).

Reduced productivity of NC machines can be traced to set up error, program error, or operator error, or managerial or procedural inefficiency. The greatest problem is in fixtures and tooling. If users were to use more efficient feeds and speeds and eliminate wasted moves and modify the machining methods, the cycle time could be reduced considerably while also cutting tool wear and breakage rates.

199. Zimmers, E. W., Jr., Metal Cutting and the Application of Computer Technology, SME Tech. Paper No. MS75-401 (Society of Manufacturing Engineers, Dearborn, Mich., 1975).

The applications of computers to improvement of steel machining efficiency and to the investigation of basic metal cutting processes are examined. Included are tracking cutting conditions by minicomputer, computer control of chatter in machining, interactive graphics for tool analysis, cutting rates, calculations and standard data systems, flexible manufacturing systems, integrated computer systems, process planning, and a forecast of future trends. 


\begin{tabular}{|c|c|c|c|}
\hline $\begin{array}{l}\text { U.S. DEPT. OF COMM. } \\
\text { BIBLIOGRAPHIC DATA } \\
\text { SHEET }\end{array}$ & $\begin{array}{l}\text { I. PUBLICATION OR REPORT NO. } \\
\text { NBSIR } 78-1424\end{array}$ & $\begin{array}{l}\text { 2. Gov't Accession } \\
\text { No. }\end{array}$ & 3. Recipient's Accession No. \\
\hline \multirow{2}{*}{\multicolumn{3}{|c|}{$\begin{array}{l}\text { 4. TITI.E. AND SUBTITLE } \\
\text { Bibliography and Brief Review of Literature on Machine-Tool } \\
\text { Measurements for Automatic Control }\end{array}$}} & $\begin{array}{l}\text { 5. Publication Date } \\
\text { April } 1978\end{array}$ \\
\hline & & & $\begin{array}{l}\text { 6. Performing Organization Code } \\
425.03\end{array}$ \\
\hline \multicolumn{3}{|c|}{$\begin{array}{l}\text { 7. A!ITHOR(S) Carol F. Vezzetti. J. Franklin Mavo-Wells, } \\
\text { John S. Hilten, ana Paul S. Lederer }\end{array}$} & 8. Performing Organ. Report No. \\
\hline \multirow{2}{*}{\multicolumn{3}{|c|}{$\begin{array}{l}\text { 9. PERFORMING ORGANIZATION NAME AND ADDRESS } \\
\text { NATIONAL BUREAU OF STANDARDS } \\
\text { DEPARTMENT OF COMMERCE } \\
\text { WASHINGTON, D.C. } 20234\end{array}$}} & $\begin{array}{l}\text { 10. Project/Task/Work Unit No. } \\
4253104\end{array}$ \\
\hline & & & 11. Contract/Grant No. \\
\hline \multirow{2}{*}{\multicolumn{3}{|c|}{$\begin{array}{l}\text { 12. Sponsoring Organization Name and Complete Address (Street, City, State, ZIP) } \\
\text { Office of Developmental Automation and Control Technology } \\
\text { Institute for Computer Sciences and Technology } \\
\text { National Bureau of Standards } \\
\text { Washington, D.C. } 20234\end{array}$}} & $\begin{array}{l}\text { 13. Type of Report \& Period } \\
\text { Covered NBSIR } \\
12-1-76 \text { to } 4-30-77\end{array}$ \\
\hline & & & 14. Sponsoring Agency Code \\
\hline
\end{tabular}

15. SUPPLEMENTARY NOTES

16. ABSTRACT (A 200-word or less factual summary of most significant information. If document includes a significant bibliography or literature survey, mention it here.)

An English-language literature survey focused on machine-tool measurements related to wear was undertaken to ascertain the types of sensors used and measurements made by investigators throughout the world in support of machine-tool automation. The resulting review and bibliography constitute this document.

17. KEY WORDS (six to twelve entries; alphabetical order; capitalize only the first letter of the first key word unless a proper name; separated by semicolons)

Adaptive control; bibliography; control; cutting force; dynamic; force; load; machine tool; measurement; review; tool wear; torque.
18. AVAILABILITY

$$
[X] \text { Unlimited }
$$

For Official Distribution. Do Not Release to NTIS

Order From Sup. of Doc., U.S. Government Printing Office Washington, D.C. 20402, SD Cat. No.C13

$x$ Order From National Technical Information Service (NTIS) Springfield, Virginia 22151

\begin{tabular}{|l|c|}
\hline $\begin{array}{l}\text { 19. SECURITY CLASS } \\
\text { (THIS REPURT) }\end{array}$ & 21. NO. OF PAGES \\
UNCL ASSIF IED & 54 \\
\hline $\begin{array}{l}\text { 20. SECURITY CLASS } \\
\text { (THIS PAGE) } \\
\text { UNCLASSIFIED }\end{array}$ & 22. Price \\
$\$$ & USCOMM-DC 29042-P74 \\
\hline
\end{tabular}


